\title{
Why do startups pursue initial coin offerings (ICOs)? The role of economic drivers and social identity on funding choice
}

\author{
Magnus Schückes (D) Tobias Gutmann (D)
}

Accepted: 23 January 2020 / Published online: 4 May 2020

(C) The Author(s) 2020

\begin{abstract}
Initial coin offerings (ICOs) are a novel form of funding that has driven billions of dollars into the blockchain ecosystem, potentially challenging traditional funding vehicles such as business angel or venture capital investments. However, little is known of entrepreneurs' rationales for leveraging this emerging form of financing. This article investigates the economic and behavioral factors that motivate entrepreneurs to fund their startup operations with ICOs. By conducting indepth interviews with C-level managers or founders of ICO-funded startups, our analysis reveals four dimensions that have an impact on the decision: (1) funding, (2) community building, (3) tokenomics, and (4) personal and ideological drivers. Our findings suggest that the entrepreneur's social identity in conjunction with the enabling mechanisms of the blockchain technology shape entrepreneurial pursuits and funding choice. We contribute to the literature on entrepreneurial finance by increasing understanding of ICOs and to the literature on entrepreneurial decision making by providing qualitative insights into the influence of founder identity on key decisions in startups such as financing.
\end{abstract}

\footnotetext{
M. Schückes $(\bowtie)$

Institute for SME Research and Entrepreneurship, University of Mannheim, Mannheim, Germany

e-mail: schueckes@bwl.uni-mannheim.de

T. Gutmann

EBS Business School, EBS Universität für Wirtschaft und Recht, Oestrich-Winkel, Germany

e-mail: tobias.gutmann@ebs.edu
}

Keywords Initial coin offerings · Entrepreneurial finance $\cdot$ Entrepreneurial decision making $\cdot$ Social identity Digital entrepreneurship $\cdot$ Blockchain

JEL classification M13 $\cdot$ M15 $\cdot \mathrm{G} 23 \cdot \mathrm{G} 32 \cdot \mathrm{L} 17 \cdot \mathrm{L} 26$

\section{Introduction}

The growth of small firms is often constrained by internal financing (Carpenter and Petersen 2002). Especially for capital-intensive, high-technology startups, financing is vital to compete and survive in the marketplace (Colombo and Grilli 2007). One of the most fundamental, yet often most difficult, steps for entrepreneurs is to find and choose from among different sources of capital to fund their startup, as this decision can have an impact on future startup growth and success (Cassar 2004; Schwienbacher 2013).

Leveraging the blockchain technology, startups have only recently started to fund their operations with initial coin offerings (ICOs), oftentimes also referred to as token sales (Fisch 2019). In ICOs, entrepreneurs distribute digital assets - such as coins and tokens - to investors (hereafter also called token holders) in exchange for capital. These tokens take on different functions and utilities within the issuer's network as soon as the project is launched. In many regards, ICOs differ from prominent funding vehicles such as business angels (BA) and venture capital (VC). The funding amounts in ICOs exceed most investment rounds by traditional funding vehicles, especially compared to early-stage 
seed rounds (Boreiko and Sahdev 2018). ICOs are also distinct from traditional crowdfunding insofar as the blockchain technology transfers some of its implications and characteristics, e.g. transparency, immutability, decentralization, and openness, to properties of the ICO (Kher et al. 2020). These technological features may not only pose certain restrictions on who can leverage this technology to their favor (Nambisan 2017) but also attract a different set of investors (Fisch et al. 2019). In this regard, ICOs represent a social and technological innovation. It is well-noted that the analysis of such new phenomena can serve as a valuable setting and opportunity to apply and extend existing theories (Makadok et al. 2018).

The literature on entrepreneurial finance in regard to ICOs is developing quickly (Adhami et al. 2018; Fisch 2019; Huang et al. 2019; Masiak et al. 2019). With more startups utilizing this funding vehicle, the research relevance of the topic for the field of not only entrepreneurial finance but also entrepreneurial decision making is becoming increasingly apt. How entrepreneurs choose from among funding alternatives has been investigated in the academic literature with a focus on capital structures, the choice between equity and debt financing, and the intersection between financing demand and supply (Scherr et al. 1993; Chaganti et al. 1995; Winton and Yerramilli 2008; Robb and Robinson 2014). Popular theoretical frameworks such as pecking order theory (Myers 1984; Myers and Majluf 1984), however, are limited for explaining funding choice. As Myers (1984) notes himself: "the pecking order hypothesis can be quickly rejected if we require it to explain everything" and, more importantly, it only serves as "a description of typical behavior" (p. 582). We know that, after all, entrepreneurs oftentimes exhibit atypical decision making behavior due to uncertainty, ambiguity, and risk involved in entrepreneurial ventures (Busenitz and Barney 1997; Sarasvathy 2001; Baron 2008). Pecking order theory, in contrast, primarily makes predictions based on information asymmetry and the cost of capital, thereby ignoring different supply sources of funding as well as demand-side considerations and motives for choosing specific sources. As Cassar (2004) points out, the dominance of the founders as the primary decision makers in a startup raises questions about their personal role and influence over funding choice which is not considered in capital structure theories. Decision criteria and characteristics of the demand side, especially concerning the role of the founders and/or CEO, are underexplored in the entrepreneurial finance literature and become more relevant in the light of novel and innovative funding sources such as crowdfunding or ICOs. Building on this idea, some authors have already hinted at the entrepreneur's perception of the startup, entrepreneurial orientation, and personal control preferences as further non-financial determinants beyond the cost of capital (Chandler and Hanks 1998; Eckhardt et al. 2006; Vaznyte and Andries 2019).

These theoretical as well as conceptual tensions, in conjunction with the growing anecdotal evidence and importance of ICOs for entrepreneurial finance, motivated our research endeavor in understanding entrepreneurial funding choice. To date, the literature on ICOs has provided valuable insights into this novel phenomenon (Adhami et al. 2018; Fisch 2019; Huang et al. 2019; Masiak et al. 2019). Yet, the underlying motivations and reasons for ICOs, which constitute the research interest of this qualitative study, are still unclear. Therefore, in this paper we address the following question: what are the economic and behavioral drivers that motivate an entrepreneur's choice of funding via an ICO?

In addressing this question, we follow recent calls from scholars to investigate the impact of digital technology on entrepreneurial processes (Nambisan 2017), new funding opportunities for entrepreneurs (Drover et al. 2017), as well as how entrepreneurs assess and choose among these sources (Shepherd et al. 2015). We draw from research in the entrepreneurial finance (Block et al. 2018a; Cumming and Groh 2018) and entrepreneurial decision making literature (Shepherd et al. 2015; Koudstaal et al. 2018; Markowska et al. 2018) while framing our discussion with social identity theory (Ashforth and Mael 1989) to evaluate why startups decide to pursue an ICO.

To answer our research question, we conducted 37 semi-structured interviews with $\mathrm{C}$-level managers (i.e., senior management such as CEO, CTO, COO) or founders of ICO-funded startups and experts. Utilizing a multiple case-study strategy (Eisenhardt 1989; Yin 2003) and adopting a qualitative perspective, we inductively uncover the different motives, as well as the economic and behavioral drivers of entrepreneurs and startups in choosing ICOs as a means of capital funding.

Following a structured and rigorous methodology for analyzing our data as established by Gioia et al. (2013), we derive four main dimensions, which serve as the constitutive elements of our model of why startups 
decide to perform an ICO: (1) funding, (2) community building, (3) tokenomics, and (4) personal and ideological drivers. These dimensions can be understood as financially as well as personally driven and thus reflect the behavioral and economic factors that motivate startups and founders to opt for an ICO. Our findings suggest that entrepreneurs' rationales for pursuing an ICO cover a multifaceted spectrum, which diverges from the single purpose of funding the startup. By not fitting the traditional characteristics and performance criteria of venture capitalists, the blockchain ecosystem and respective entrepreneurs developed their own social identity, which is reflected in different approaches to entrepreneurial judgment, choice and management and consequently affects funding choice.

Beyond filling a void in the literature in entrepreneurial finance to help demask ICOs as a new phenomenon and source of capital, this exploratory research makes additional contributions to the entrepreneurship literature and to our framing theory. First, we extend research on entrepreneurial decision making (Shepherd et al. 2015), showing that entrepreneurs' rationales for pursuing an ICO go beyond financing the startup. While economic drivers or the perception of the startup and surrounding market has been the focus of the respective literature stream, we demonstrate that behavioral and ideological motives play distinct roles in funding choice that have not been captured by relevant capital structure theories and draw parallels to the emerging literature on entrepreneurial identity. Second, and related to this, we contribute to social identity theory in entrepreneurship and to the identity perspective on entrepreneurial behavior (Fauchart and Gruber 2011; Gruber and MacMillan 2017) by offering further insights into the influence of founder identity on key decisions in startups such as financing. Our evidence indicates a strong ideological divide between the blockchain community and conventional entrepreneurship, which segregates these entrepreneurs from traditional funding vehicles. Entrepreneurs in the blockchain ecosystem show considerable tendencies to follow the narrative surrounding the invention of Bitcoin, which was built on the premise of superseding the current financial system and a more transparent society. Personal beliefs and values of the entrepreneur, and hence decision making, are thus influenced by this cult-like account, in conjunction with legitimacy concerns. Lastly, we can expand on the growing stream on digital entrepreneurship (Nambisan 2017). As a new form of digital technology, the blockchain shows a considerable impact on shaping entrepreneurial pursuits and processes. It reconfigures the locus of entrepreneurial agency as it enables nonconventional founders to get access to financial and non-financial resources and further develop their ideas, thereby deviating from more traditional pathways to entrepreneurship. The technology further redefines the boundaries of agency as it is able to incorporate a diverse range of stakeholders, incentivize them, and democratize decision making in a startup, therefore leading to community-building and a more collective way of engaging in entrepreneurship. These technological shifts go hand in hand with the abovementioned social identity of the founders and entrepreneurs: community building, shared value creation, and a joint mission and belief system shape the economic and sociotechnical interactions between founders, community, and technology. The ICO becomes a manifestation of the underlying technology, but also of the social ecosystem.

\section{Background}

\subsection{Entrepreneurial finance and funding choice}

Research on entrepreneurial finance has highlighted several sources of financing for startups and entrepreneurs, namely banks, family and friends, business angels, and venture capital (Drover et al. 2017). Over the years, new ways to raise capital have emerged (e.g., crowdfunding) and new investment opportunities have been introduced (Block et al. 2018a). Based on these developments, Drover et al. (2017) propose studying new sources of capital, especially how these "complement or challenge existing theories and assumptions" ( $p$. 1843). As the range of funding opportunities widens for the entrepreneur, it becomes imperative to understand the interdependencies and implications of each funding vehicle for the startup and how entrepreneurs choose among them.

Logic from pecking order theory suggests that a firm's funding decision is largely based on decreasing the cost of capital associated with respective financing sources (Myers 1984; Myers and Majluf 1984). Firms will thus prefer to fund their operations with internal funds before selecting debt or equity financing, as asymmetrical information costs create obstacles to external funding. While Winton and Yerramilli (2008) find that 
startups and small businesses might opt for equity over debt financing, especially for high-risk and uncertain strategies that have only a low probability of success, extant research has shown that the pecking order theory also holds for small firms (Degryse et al. 2012) and for new and high-tech ventures (Vanacker and Manigart 2010; Robb and Robinson 2014). Pecking order theory might, however, not fully explain funding choice. Myers (1984) notes that the pecking order hypothesis is insufficient to explain funding choices of the whole population of firms, but only accounts for "typical behavior" (p. 582). It is questionable whether startups fall under this definition as entrepreneurs frequently display different decision making behavior accounting for the distinct nature of their uncertain and risky venture (Busenitz and Barney 1997; Sarasvathy 2001; Baron 2008). This point is also stressed by Cassar (2004) who argues that the role of the entrepreneur is of particular importance in financing decisions and following young firms in detail "may increase understanding of the motivations for searching for different types of finance and the nature of such searches" (p. 279). In this regard, scholars found evidence for the existence of several types of entrepreneurs and different entrepreneurial identities that stress social and educational aspects (Fauchart and Gruber 2011).

We expect that the entrepreneurs' personal and behavioral motives have a distinct influence on decision making. Several entrepreneurs' characteristics have been theorized or found to play a role in funding choice such as the entrepreneurs' attitudes towards maintaining managerial control within their startup (Alvarez and Parker 2009), their perception of the market (Eckhardt et al. 2006), or the entrepreneurs' perceived risk attitude which is a function of an entrepreneur's personal characteristics and experience (Schwienbacher 2007). The latter can also be related to Seghers et al. (2012), who show that management and industry experience, financial networks, and prior business education determine funding decisions (see also Gartner et al. 2012). Extant research in this field is predominantly focused on businessrelated drivers (Scherr et al. 1993; Chaganti et al. 1995; Schwienbacher 2007; Robb and Robinson 2014). Beyond capital structure theories, scholars have drawn on learning models and theories (Cyert and DeGroot 1987; Cohen and Levinthal 1990), multistage selection processes (Aldrich 1999), or the real options approach (McGrath 1999).
New forms of funding are inciting researchers to study and "explore the drivers behind why entrepreneurs select different forms of [...] funding" (Wright et al. 2016, p.231), as well as how different forms of funding complement or substitute each other (Cumming and Groh 2018), as they may attract a different set of entrepreneurs "who are younger, more computer literate, and more connected" (Shepherd et al. 2015, p. 26) and have a different set of personal drivers. In this regard, ICOs are an emerging topic in the entrepreneurial finance landscape, especially in conjunction with a rising interest in blockchain technology and digital technologies in general (Nambisan 2017).

\subsection{Blockchain and distributed ledger technology}

With the introduction of Bitcoin, Satoshi Nakamoto (2008) proposed a radically new distributed protocol (known as blockchain and distributed ledger technology) ${ }^{1}$, enabling consensus in permission-less settings (i.e., digital environments in which anyone can join a network without disclosing his or her identity). By using cryptographic hash functions, computational puzzles and economic incentives, Nakamoto designed a distributed public ledger that creates trust among participants without the need for intermediaries or central authorities. Transactions are recorded in blocks and broadcast to all participants in the network (called "nodes") for verification of validity. As soon as consensus about the state of the ledger is reached by a majority of participants in the network, the transactions are permanently recorded in a transparent and verifiable manner, excluding subsequent modification or deletion.

The blockchain technology has been called "disruptive" (Mattila 2016, p. 4), a "digital revolution" (Wright and De Filippi 2015 p.2), a "new engine of growth" (Crosby et al. 2016, p.9), and a "magic global computer" (Buterin 2015). While the economic value of Bitcoin and other cryptocurrencies, which Fisch et al. (2019) defined as a "digital medi[a] of value exchange based on the distributed ledger technology" (p. 2), is debatable, blockchain technology has proven to be secure and useful. Many public companies and syndicates such as the Hyperledger project are opening up to blockchain

\footnotetext{
${ }^{1}$ We are aware of the differences between blockchain and distributed ledger technology. For simplification, we use both terms interchangeably.
} 
and are investigating use cases and applications for their own operations and processes (Cachin 2016).

Beyond currencies, smart contracts are an important property of blockchains. With platforms such as Ethereum, literally anybody can create their own token or cryptocurrency and set up smart contracts, which are programs that automatically execute the contract once its object of agreement occurs (Buterin 2014). ICOs are, in this regard, an upcoming development also driving the popularity of cryptocurrencies, especially Ethereum (Pietrewicz 2018).

\subsection{Initial coin offerings}

The increasing prevalence of ICOs has given rise to nascent research on this rather unexplored topic. To date, research examining ICOs has provided novel insights by focusing on success factors (Adhami et al. 2018; Amsden and Schweizer 2018; Fisch 2019), the geographical dispersion (Huang et al. 2019), or market cycles and investor sentiment related to ICOs (Drobetz et al. 2019; Masiak et al. 2019). Despite ICO's promising relevance for entrepreneurial finance and entrepreneurship, the peer-reviewed literature is still scarce. We plan to contribute to this growing line of inquiry by increasing our understanding of the motives of entrepreneurs to opt for ICOs as a funding vehicle.

ICOs have been defined as an open call for funding (Adhami et al. 2018) and an unregulated token sale to a crowd of investors in exchange for capital funding (Fisch 2019). Tokens issued in an ICO can represent different characteristics and rights to the holder, such as asset rights (representing ownership of or a claim on a physical good on the blockchain), usage rights (representing access to a service, similar to a coupon or pre-sales-based crowdfunding), or work rights (representing the contribution of work to a decentralized network). Consider the examples of Swiss-based blockchain startup Orocrypt, which released a token representing the ownership of $30 \mathrm{~g}$ of bullion gold (asset right); Irish-based startup Cloud With $\mathrm{Me}$, which offered a token representing access to distributed cloud services (usage right); and US-based startup Protocol Labs, which issued a token that a service provider stakes to earn the right to perform work for the network (work right). In all of these cases, the token does not represent direct control over the company. Due to regulatory concerns, the vast majority of ICO-funded startups refrains from issuing equity and securities via token sales.
Recently, however, startups have begun to move in this direction by funding themselves via so-called security token offerings (STOs), which can be regarded as an advancement in the evolution of ICOs.

ICOs are credited with having the "potential to democratize innovation" and "reshape [...] entrepreneurship" (Chen 2018, p. 567), as they provide investors around the globe the significant upside potential of early-round investments and enable startups to share wealth among developers, early adopters, and investors (Chen 2018). For startups, ICOs are cheaper, faster, and less troublesome compared to traditional funding alternatives and have been described as one of the most efficient means of financing entrepreneurial initiatives, as they minimize transaction costs and disintermediate banking. Catalini and Gans (2018) show that tokens can also help to foster network effects and coordinate stakeholders within the blockchain ecosystem. In contrast, token holders are exposed to significant investment risks with no ability to control the startup and no protection in case of bankruptcy. Furthermore, investors often invest in early-stage projects that offer barely more than a future promise or idea. Also associated with the lack of a product or prototype is a more general lack of information and uncertainty stemming from information asymmetry (Adhami et al. 2018, Pietrewicz 2018).

A typical ICO is usually announced with the disclosure of a white paper that describes the token sale, the underlying IT protocol and blockchain, the project, and the business model. It also describes the distribution and function of the token, its holder's rights, and its value. The number of tokens is usually limited, with a set funding limit. The most common way to offer tokens is via auction, with proceeds going towards funding a startup or project (Conley 2017). An excellent overview of what constitutes an ICO can be found in Howell et al. (2018) as well as in Boreiko and Sahdev (2018). The latter authors further elaborate the evolution of the ICO and highlight the features of different development stages.

Several authors have conducted empirical research on ICOs with a focus on determinants and success factors of token offerings (Adhami et al. 2018; Amsden and Schweizer 2018; Blaseg 2018; Boreiko and Sahdev 2018; Fisch 2019; Howell et al. 2018; Momtaz 2018). We summarize these findings in Table 1. Due to the unregulated nature of ICOs, there is no complete and well-established database on ICOs, making data collection difficult and time-consuming. Hence, the sample size and quality differ widely across these 
Table 1 Overview on literature about success factors in initial coin offerings

\begin{tabular}{|c|c|c|}
\hline Author & Sample & Findings \\
\hline $\begin{array}{l}\text { Adhami et al. } \\
\text { (2018) }\end{array}$ & $\begin{array}{l}\text { Hand-collected dataset with } 253 \text { ICOs from } \\
2014 \text { to August } 2017\end{array}$ & $\begin{array}{l}\text { The authors find a high success rate for ICOs in general. Funded projects } \\
\text { are largely blockchain or fintech related. The majority of distributed } \\
\text { tokens serve as utulity tokens. } \\
\text { ICO success (ICO completed) is attributed to: } \\
\text {-Disclosure of source code } \\
\text {-Pre-sale } \\
\text {-Utility of token }\end{array}$ \\
\hline $\begin{array}{l}\text { Amsden and } \\
\text { Schweizer } \\
(2018)\end{array}$ & $\begin{array}{l}\text { Hand-collected dataset from ICObench.com } \\
\text { and Cryptoslate.com with } 1009 \text { ICOs }\end{array}$ & $\begin{array}{l}\text { Based on the literature on venture and crowdfunding selection, the authors } \\
\text { find that success (conceptualized as listing on exchange) is: } \\
\text {-Attributed to management team (large team size, network) } \\
\text { - Negatively correlated to venture uncertainty (no social media presence, } \\
\text { short white paper, more tokens distributed) }\end{array}$ \\
\hline Blaseg (2018) & $\begin{array}{l}\text { Hand-collected dataset with } 1104 \text { ICOs from } \\
\text { January } 2014 \text { to December } 2017\end{array}$ & $\begin{array}{l}\text { Drawing on information economics theories on signaling and unraveling, } \\
\text { the author finds that success (conceptualized as listing on exchange) is } \\
\text { attributed to: } \\
\text {-Quality disclosures (disclosure of source code) } \\
\text { - Team composition }\end{array}$ \\
\hline $\begin{array}{l}\text { Fisch et al. } \\
\text { (2019) }\end{array}$ & $\begin{array}{l}\text { Hand-collected dataset with } 423 \text { ICOs from } \\
\text { March } 2016 \text { to March } 2018\end{array}$ & $\begin{array}{l}\text { Using signaling theory, the author finds that success (amount raised) is } \\
\text { attributed to: } \\
\text {-Communication activity } \\
\text {-ICO characteristics (i.e., duration, number of tokens created, } \\
\text { technological basis) } \\
\text {-Jurisdiction of startup } \\
\text {-White paper }\end{array}$ \\
\hline $\begin{array}{l}\text { Howell et al. } \\
\qquad(2018)\end{array}$ & $\begin{array}{l}\text { Hand-collected dataset with } 453 \text { ICOs } \\
\text { between } 2013 \text { and January } 2018\end{array}$ & $\begin{array}{l}\text { Liquidity and trading volume are higher for tokens that: } \\
\text {-Offer voluntary disclosure (disclose source code, publish white paper, } \\
\text { publish use of proceeds) } \\
\text {-Engage with their community (followers on Social Media) } \\
\text { - Credibly commit to the project (insider vesting schedule) } \\
\text {-Signal quality (entrepreneurial background, prior VC investment, } \\
\text { pre-sale, new blockchain protocol, clear utility for token) }\end{array}$ \\
\hline Momtaz (2018) & $\begin{array}{l}\text { Icobench.com dataset with } 2131 \text { ICOs from } \\
\text { August } 2015 \text { until April } 2018\end{array}$ & $\begin{array}{l}\text { The author finds that the market liquidity hypothesis holds in ICOs by } \\
\text { studying first-day returns. Success (first-day returns) is positively } \\
\text { affected by: } \\
\text { •Quality of management team* } \\
\text {-ICO profile (based on expert rating from ICObench) }\end{array}$ \\
\hline
\end{tabular}

publications, resulting in different opinions on what constitutes a successful ICO. However, certain common characteristics and success factors are identified. Among these, the disclosure of the source code and white paper, the quality of the management team and ICO-related factors such as vesting schedules, the proportion of tokens sold to the public, and the utility of the token were mentioned most often.

We regard ICOs as a novel and compelling research arena for inquiries into entrepreneurial finance and decision making. While the number of ICOs in previous years grew at a slow pace, 2017 saw a significant expansion with around 400 ICOs, making it a mainstream phenomenon in the blockchain ecosystem. Despite the lack of clear regulation or oversight, hundreds of startups have announced or conducted ICOs so far. According to the ICO tracking website coinschedule. com, more than USD 31 billion were raised via ICOs (03/2020) since 2016. The sheer magnitude of funding for early-stage blockchain startups does not compare to any other funding alternative for similar endeavors. Further, ICOs seem to draw heavily on the technological features and properties of the blockchain technology, which has the possibility to create transparency, 
immutability, decentralization, and openness in the funding process, something which is rather uncommon in the entrepreneurial finance landscape. The effect of these properties on the funding process is unknown.

Given the limited explanatory power of existing capital structure theories on the choice of funding sources (Myers 1984), and the considerable role of the entrepreneur in decision making (Cassar 2004), understanding the economic and behavioral drivers behind the choice of a new funding source can deepen our knowledge in entrepreneurial finance by demasking the ICO as a phenomenon, but also help to contribute to theory building.

\section{Methodology}

\subsection{Research design}

The focus of this study is to develop a richer understanding of ICOs as a new and rather unexplored phenomenon. Considering the exploratory nature of this research topic, the novelty of ICO in academic research as well as the limited understanding of why founders opt for ICO funding, we use a multiple case-study strategy (Eisenhardt 1989; Yin 2003). We subscribe to the notion that new phenomena are best understood by qualitative and inductive research. Thus, we pursue our investigation inductively and adopt a qualitative perspective (Corbin and Strauss 1998) to discover the different economic and behavioral drivers of entrepreneurs and startups in choosing ICOs as a means of capital funding.

The gold rush caused by soaring cryptocurrency valuations has created a great deal of noise and controversy in the entrepreneurial community where ICOs are concerned. We recognize that the world around us, especially the blockchain and cryptocurrency ecosystem, is socially constructed and subject to complex social patterns. This recognition leads to the belief that an interpretivist view is best suited for capturing this complex phenomenon, as it attempts to seize the experience, opinions, and interpretations of informants without shaping their views with prior theoretical concepts. Following Gioia et al. (2013), we assume that informants are "knowledgeable agents" who can describe their underlying motivations and rationale for their decision making.

\subsection{Sampling process}

We focus on ICO-funded startups using a handcollected data set by Boreiko and Sahdev (2018) covering ICOs from January 2013 to September 2017. The data was collected from Smith\&Crown, Tokenmarket, Icobazaar, and Coinschedule. These are dedicated ICO tracker websites that we consider to be the most credible and complete sources and are also used by other researchers in this field (Fisch 2019). The data was further enriched with information from the official websites of respective startups, their social media presence, forums, and press releases.

The initial sample yielded 383 ICO-funded startups, of which we deemed 50 to be scam attempts. To obtain first-hand information on the economic and behavioral drivers and motives for an ICO, we deliberately targeted either C-level managers or founders and excluded startups where we could not access these informants. A further 143 companies were excluded from the sample as they did not provide sufficient contact details. We used purposeful sampling for the remaining companies to identify a diverse set of cases and thereby tried to increase variation among the subjects of interest in terms of the year of the ICO, amount raised, and prior VC funding. Due to the novelty of this topic, we sought to obtain the broadest range of information and perspectives as possible. We contacted companies via email, LinkedIn, Slack, and Telegram.

We conducted interviews with 30 ICO-funded startups. Moreover, as the blockchain scene is wellconnected, we leveraged the snowball sampling strategy. Interviewees were asked to name startups and founders who would be of interest for our research. From this method, we gained access to seven additional experts that we interviewed for this study. The total sample size thus consists of 37 interviews.

As a control mechanism, we tested for selection bias using a binominal logit model computed on a database of 333 firms that constituted the population of interest for our study. We designated the year of the ICO, the publication of a white paper (as an indicator for transparency), the total amount raised in Bitcoin and USD (as an indicator for success), and prior VC funding (as an indicator for investor outreach) as predictors. None of these variables emerged as a significant predictor $(p>.05)$ of inclusion in our sample (coded " 1 " for 
inclusion). This indicates that firms included in our sample are unlikely to differ systematically from firms that were not included.

Descriptive statistics of our final sample are as follows: respondents' firms conducted their ICO in 2017 (20), 2016 (6), 2015 (2), 2014 (1), and 2013 (1). Our sample reflects the different waves of ICOs that were conducted in this time frame (Boreiko and Sahdev 2018). We interviewed four respondents whose firm raised less than USD 50,000, seven who raised up to USD 1 million, thirteen who raised up to USD 10 million, and four who raised more than USD 10 million up to about USD 26 million. For two cases, the amounts raised were not disclosed. The startups of 28 respondents published a white paper, while seven startups disclosed prior $\mathrm{VC}$ funding.

\subsection{Data collection}

Given the limited research in this domain, we did not propose specific hypotheses or strict interview guidelines. However, since ICOs can be closely related to the emerging literature on crowdsourcing and crowdfunding, as well as on entrepreneurial finance in general, we used general themes and findings in this field to develop our interview guide (e.g., Belleflamme et al. 2010; Schwienbacher and Larralde 2012; Gerber et al. 2012; Moritz and Block 2016).

For the data collection, semi-structured interviews were utilized as they serve the "purpose of obtaining descriptions of the life world of the interviewee in order to interpret the meaning of the described phenomena" (Kvale and Brinkmann 2009, p.3). By applying semi-structured interviews, we were able to reap the benefits of acquiring an emic understanding of the phenomenon from the interviewees themselves, as semi-structured interviews focus on a subject's experience and knowledge of a theme and draw on their own perspective (Kvale and Brinkmann 2009). The interview guide was initially tested with three pilot interviews and consequently adapted.

We conducted interviews between June 2018 and September 2018. The interviews took an average of $39 \mathrm{~min}$, ranging from 21 to $72 \mathrm{~min}$. The interviews conducted yielded more than $24 \mathrm{~h}$ of tape-recorded interviews that were transcribed into 426 pages of text. All interviews were coded. The first ten interviews were simultaneously conducted by two interviewers to reduce the risk of interviewer bias. Moreover, we wanted to maximize replication logic and thus established a common research orientation and research protocol (Yin 2003). We conducted subsequent interviews with single interviewers.

\subsection{Data analysis}

Our structured data analysis follows the "Gioia Methodology" (Gioia et al. 2013). Although this research design dates back to early ethnographic studies by Gioia and Chittipeddi (1991) and Gioia et al. (1994), it only recently gained popularity in a wide range of qualitative entrepreneurship studies (e.g., Miozzo and DiVito 2018), particularly in the still nascent research on crowdfunding (e.g., McKenny et al. 2017; Block et al. 2018b; Estrin et al. 2018).

We used the computer software program MAXQDA to systemize and code the data collected. To ensure intercoder reliability, each transcribed interview was coded by the two researchers individually and the codes were subsequently compared to settle on a final interpretation. This measure of researcher triangulation was utilized to "guard against the biases associated with a single role and set of role relationships, the personal characteristics of the researcher, and his or her preferred interpretive point of view" (Lofland and Lofland 1971, p.93).

Overall, we iterated between the developing model and the data until we achieved a viable set of first-order codes, second-order themes, and aggregate dimensions. We stopped when we reached "theoretical saturation" (Glaser and Strauss 1967). For the sake of clarity, we present our analysis in three sequential steps:

First, we began to identify first-order codes by "open coding" (Corbin and Strauss 1998; Locke 2001) the individual interviews regarding the rationale and motives for blockchain startups to perform an ICO. Each researcher independently coded the data, and we then compared and refined our categorization schemes to assess reliability. The interviews yielded a database of 394 codable statements. Following Corley and Gioia (2004), each statement consisted of a sentence or paragraph conveying a coherent point about why the individual startup decided to perform an ICO (Weber 1990). These statements were categorized into mutually exclusive and collectively exhaustive first-order codes. 
Second, we built upon these first-order codes with the goal of detecting conceptual patterns and similarities. Moving from the initial open coding to axial coding (Locke 2001), we identified linkages and themes within the first-order codes to derive second-order themes (Gioia et al. 2013). For example, we aggregated statements regarding the difficulty of receiving funding from traditional institutional investors as Lack of other funding options, statements regarding the distribution of wealth as Democratization of wealth, and participation in the development of the network and startup by the community as Wisdom of the crowd.

Third, we formed aggregate dimensions by raising the level of abstraction and linking the various secondorder themes (Gioia et al. 2013) that emerged from the data (as illustrated in Fig. 1) to build the data structure. We derived four main dimensions, which serve as the constitutive elements of our model of why startups decide to perform an ICO: (1) funding, (2) community building, (3) tokenomics, and (4) personal and ideological drivers. We report the quantity and distribution of the codes in Table 2. We find that the first two dimensions had a strong prevalence in almost all interviews; the same is true for personal and ideological drivers in more than two thirds of our interviews. Tokenomics was found with the lowest frequency but was still mentioned in almost every second interview.

During this process, we spent considerable time both discussing and interpreting the data. We also discussed our emerging data structure with colleagues not involved in the study (Lincoln and Guba 1985) with the aim of ensuring the reliability of the coding.

\section{Findings}

Based on the data analysis (Fig. 1), the findings can be unpacked into four distinct dimensions: funding, community building, tokenomics, and personal and ideological drivers. We demonstrate evidence that all four dimensions play a crucial role in the choice of an ICO as a funding vehicle. We describe the themes within each dimension in the following.

\subsection{Funding}

Funding is described as the primary motive to conduct an ICO. The way funds are raised make an ICO more attractive to founders as well as respective investors.

\subsubsection{Unlocking capital of individual investors globally}

Initial coin offerings are perceived as a superior form of traditional crowdfunding. In contrast, however, ICOs remove the necessity for an underlying intermediary platform such as Kickstarter or Indiegogo. The ability to unlock capital from a wide range of individual investors on a global scale creates more funding opportunities in terms of project range and scale, without the limitations and costs imposed by a crowdfunding platform. As one founder said: "ICOs are a version of crowdfunding, but on steroids." Further, individual investors are perceived to come without the strong agenda traditional investors have and are more open to projects and ideas that would not get funded under a traditional venture capital regime, such as open source projects or projects that are difficult to commercialize. This also includes startups from countries that do not have access to institutional money or are not on the radar of venture capitalists due to a small market or a lack of financial infrastructure (e.g., Eastern Europe). An ICO makes the location of the startup irrelevant. In fact, many startups in our sample could not be allocated to a particular geographical location or country as they were often composed of many employees and entities forming virtual teams across different regions.

\subsubsection{Creating liquidity}

Most of the sampled startups issued utility tokens, which represent access to a product or service that the startup is going to provide in the future. Due to the nature of the blockchain, many products and services can become more valuable as network effects come into play. While investors may not have a claim on the startup's assets, they profit from a growing network and increased usage of the service as the token appreciates in value. The ability to tokenize products and services creates direct liquidity for traditionally rather illiquid assets. Many startups exploit this token characteristic by listing the token on cryptocurrency exchanges. The cryptocurrency tracking website coinmarketcap.com currently (03/2020) keeps record of more than 2000 different coins and tokens that are tradable on one of many cryptocurrency exchanges. This gives investors the opportunity to enter and exit on the spot and attracts capital. For certain startups, the possibility to set a market price for their products was crucial in opting for an ICO. 
1st Order

Concepts 2nd Order Themes
Aggregate Dimensions

- Tap into new set of investors

- Open for every individual investor

- Raise funds globally

- It unlocks capital

- Investment can be traded right away

- Liquidity as an innovation in the Private

Equity asset class

- Enter or exit as an investor

- Have a coin trading on an exchange

- Quick and easy way to raise capital

- Less barriers to entry

- Accessible to every startup

- Minimal efforts and resources compared to other funding vehicles

- ICO boom

- It was the thing to do at the time

- Raising millions with just a white paper

- The common way to raise funds for a crypto project

- VCs weren't looking into crypto

- VCs with no understanding of technology

- Projects have longer time horizons

- MVP required to raise capital

- Open source projects barely funded
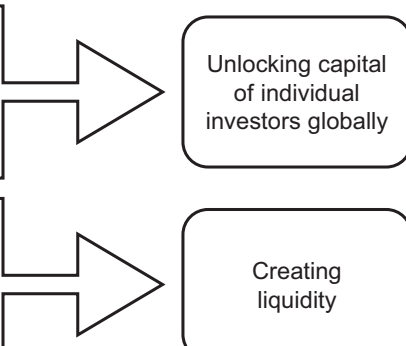

- Assess the market

- Create market prices for the product

- Enable community to test product

- Test future customers' willingness to pay

- Get the public's attention efficiently

- Create level of excitement

- Garner interest in a project

- Use ICO as marketing instrument

- Jumpstart the internal network mechanisms of the product

- Incentivize the users with tokens

- Solve chicken-or-egg problem for multi-sided platform

- Bring people on the platform

- Customers have privileged access to services

- Customers are willing to pay for their loyalty

- Bind customers with tokens

- Engage with lead users and innovators

- Community is highly educated and technically adept

- Regular feedback on product and strategy

- Build a large community with diverse skills

- Community is equivalent to a VC

- Have a sounding board on hand

Fig. 1 Data structure: concepts, themes, and dimensions
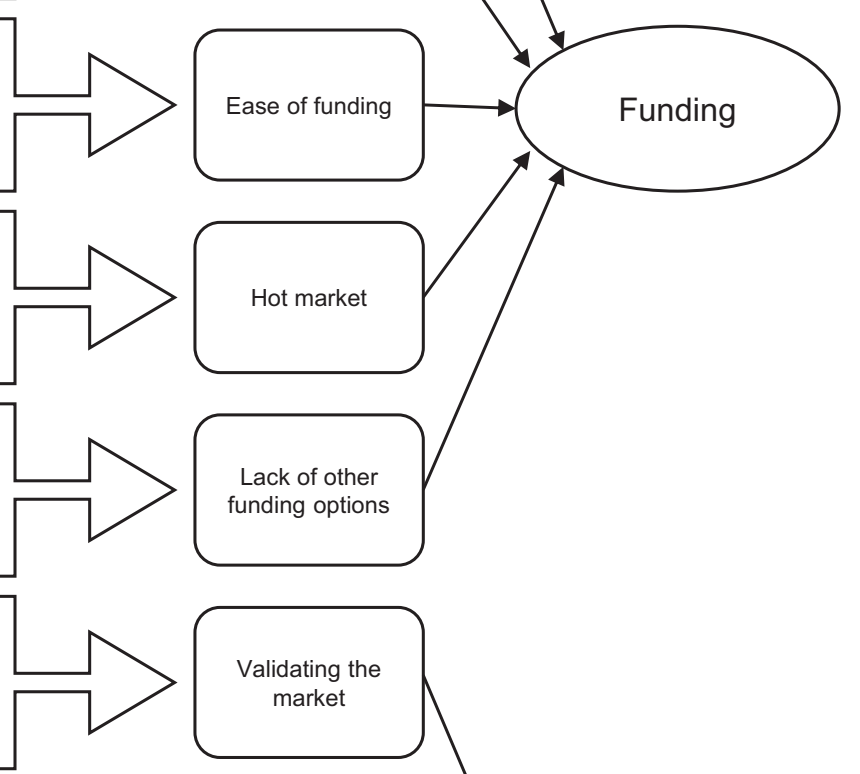


\section{1st Order}

Concepts

\section{2nd Order Themes}

\section{Aggregate \\ Dimensions}

- Protocol for decision making

- Use tokens a as a voting mechanism

- For governance of the ecosystem

- Intention to fully decentralise

- Distributed autonomous system requires a token

- Main value derived from transparency

- Deliver transparency and openness with open source technology

- Establish absolute immutability

- Value proposition requires trust

- Token is transparent, provable and traceable
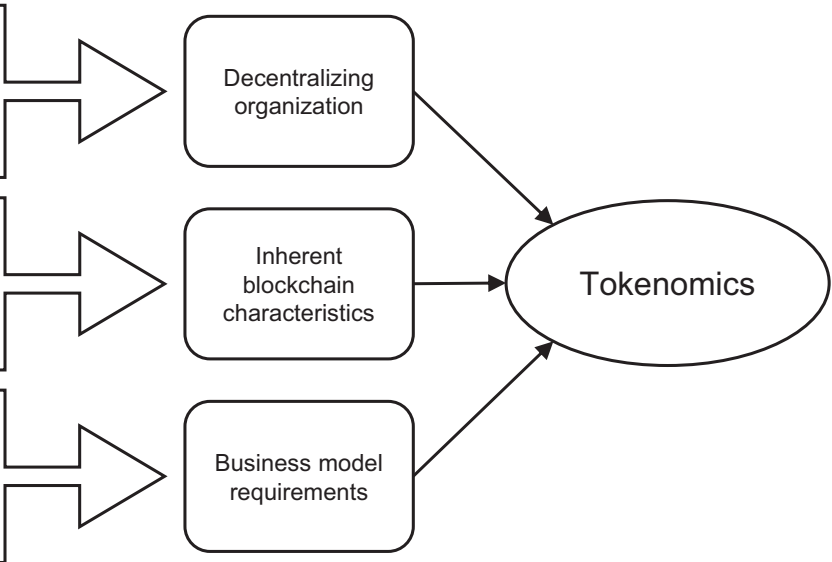

- Setup a decentralized network economy

- Cryptocurrency required to run the blockchain

- Token needed for the blockchain to operate

- Network needs a coin

- Raise capital without giving away equity and control rights

- No need to answer questions to any investor

- VC dictates terms

- Maintain more control

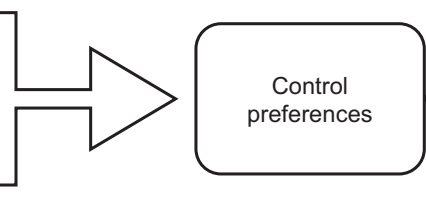

- Start project out of curiosity

- Experiment with token sale

- Get familiar with technology

- Test the waters

- An alternative economic system

- Holistic grassroots, decentralized approach

- More grassroots opposed to corporates

- Create value together in a social way

- A model that's much more democratic

- Wealth to be distributed more democratically

- Trailblaze financial freedom

- It's open to every investor

- Offering access to closed asset class

- Stands for freedom of speech, privacy, human rights

- Interest in the progress of humanity

- Try to change the world

- No need for a profit motive

- Found with social conscious element
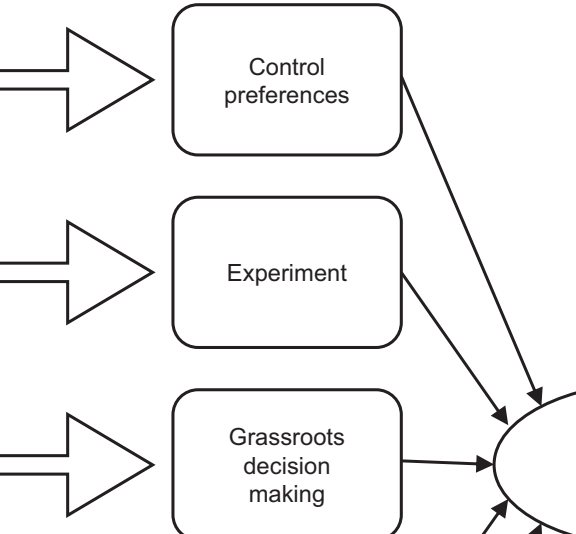

Personal and ideological drivers

Fig. 1 (continued)

Table 2 Count and distribution of codes and dimensions

\begin{tabular}{lcc}
\hline Aggregate dimension & No. of codes & Prevalence among interviews \\
\hline Funding & 166 & $34(92 \%)$ \\
Community building & 98 & $31(84 \%)$ \\
Tokenomics & 45 & $18(49 \%)$ \\
Personal and ideological drivers & 85 & $26(70 \%)$ \\
\hline
\end{tabular}




\subsubsection{Ease of funding}

The ICO was generally described as an easy and efficient funding process. Available ICO standards such as the ERC-20 token, which is based on the Ethereum blockchain, enabled even non-technical founders to issue tokens and collect funds with minimal effort and resources. One interviewee compared the simplicity of issuing coins to starting a web shop, which has become accessible to mom-and-pop stores in recent years. This creates an influx of many ideas and projects into the ICO market place, which usually do not have the opportunity to get funded by traditional means. In general, an ICO lowers barriers to entry for funding and is accessible to everyone irrespective of ethical background, education, or technical skills. This is also reflected in the variety of our interviewees ranging from the 17-year-old technically adept student to the 60-year-old asset manager. In contrast, the search for angel investors or venture capitalists is perceived as lengthy and troublesome. As one CEO put it: "You can do fundraising with Sequoia or with other incubators in five years or in three years. I do it overnight. Let's see who is faster." In particular, the time and costs required to raise traditional seed funding were a major motivator to conduct an ICO as it provides "a fast way of raising capital". It must be recognized that the ease of running a successful ICO has diminished over time as the market has matured and regulators have put pressure on startups to comply with local regulations. However, the technical ease of issuing coins remains unimpaired.

\subsubsection{Hot market}

With a volume of USD 31 billion, the ICO market has created a gold rush opportunity for startups. Attracted by the large sums raised by competing startups, many saw the ICO hype as an opportunity to exploit the prevailing market conditions. As one CEO described: "We saw groups that didn't have the technology and knowledge that we have. Some of them just had a white paper but they raised millions and millions. We started to study if we can do the same." For blockchain startups, these were also perceived as the "way [to] raise funds if you had a crypto project". This is especially true for startups that raised money before the ICO hype started in 2017.

\subsubsection{Lack of other funding options}

Seed funding by BAs and VC was not available for many blockchain startups due to several reasons. Venture capitalists were said to lack the understanding for blockchain technology and respective solutions. As one founder pointed out: "If we talked with anyone about Bitcoin, we'd need to start with the very discussion about why it is not a Ponzi-scheme, what Bitcoin is, and what we call blockchain." In other situations, blockchain developers have been shut out as "there was an immediate prejudice against crypto currencies from all traditional financial institutions," including venture capitalists. Furthermore, interviewees perceived their projects and startups as "not the rapid return on investment type model that equity investors are looking for." The development of blockchain technology can face longer time horizons than venture capitalists are willing to take. These projects usually emphasize a distributed and open source development of the technology, which constrains commercialization. Lastly, many projects start with a white paper only, while venture capitalists usually require a working product and a projected revenue stream, which are difficult to develop without proper funding in the first place: "There was no way we would have raised money with a VC to get us operational."

\subsection{Community building}

A strong community comes naturally with the development of open source projects and has a long-standing tradition in software development. This tradition is also mirrored in the evolution of the blockchain ecosystem and utilized by ICO-funded startups.

\subsubsection{Validating the market}

Startups use ICOs as a means for assessing the market potential for their ideas and business models. By selling tokens for a to-be-developed product or service to customers, startups can test market demand and determine future customers' willingness to pay without a heavy upfront investment in R\&D. A CEO drew a comparison to crowdfunding campaigns: "We were really just testing the marketplace to see if there are future customers that are willing to pay for a blockchain. We considered it like a Kickstarter project, which tries to sell watches on the market." Due to the disruptive nature of blockchain 
technology, products and services face higher risk and uncertainty compared to more traditional $\mathrm{B} 2 \mathrm{C}$ products. The token price acts as a mechanism for ascribing value to the product or service and can help startups introduce a technology while simultaneously reducing unknowns in their go-to-market strategy.

\subsubsection{Generating buzz}

Startups leverage the ICO hype not only for funding purposes but also to drive interest in their products and services. An ICO is described as an "excellent way to create that level of excitement" surrounding the launch of a new project. By jumping on the ICO bandwagon, startups can get the public's attention efficiently without excessive marketing expenditures. Additionally, the ICO creates "a huge marketing group that will help [...] launch the project." This finding can also be related to the hot market phenomenon previously described. Investors, who wanted to profit from the gold rush, worked as amplifiers for startups and became valuable sources of testimonials and social media influencers for not only a startup's product but also its respective funding campaign. In the search for a new ICO unicorn, investors created artificial hype by spreading evaluations, recommendations, and referrals across relevant social media channels.

\subsubsection{Kicking off network effect}

As a distributed ledger, most blockchain applications rely on a constant inflow and retention of participants within the network. Network effects apply here; the more users who participate in the network, the higher the utility derived for each individual user. Kicking off these network effects is generally a difficult undertaking for platforms:

"There was the question of chicken-or-egg, which is applicable to any marketplace application where you need to bring supply and demand together. So how do you do the magic circle with who comes first? [...] We wanted to create the network effect we were looking for. It was part of the deal of doing a new thing."

Selling and distributing tokens via an ICO can thus help engage users to participate within the network, as token holders will see an appreciation in the value of the token once the value of the network increases: "The token is a way to incentivize the user." Token holders, thereby, have a natural incentive to invite more users to the platform and enlarge the network, hence driving the marginal value of the platform for each user.

\subsubsection{Creating a loyal customer base}

Tokens can incentivize the user not only to participate but also to be loyal to the underlying product or service. As users have a long-term financial incentive to participate, they will likely stick with the startup and generate awareness through word-of-mouth among their peers. Furthermore, token holders can expect to have access to otherwise costly product benefits: "By holding tokens in our services, you have advantageous access to services. So, this is like your frequent flyer miles on an airline." These benefits can include price discounts and access to further product or service features, as well as a voice in the future direction of the startup's product development.

\subsubsection{Wisdom of the crowd}

Startups benefit from an ICO, as they create a large community of innovators and lead users who often share their knowledge, personal networks, and experience to guide the development of the project. Community members serve as beta testers and provide early feedback on product features and weaknesses in the system. In this sense, the community is perceived to be even more valuable than the funding and creates additional resources and capabilities, with users being directly involved and often having full responsibility for certain remits. Comparing the community to venture capitalists, many interviewees claim that the community is equivalent if not superior to the operational value venture capitalists can provide: "In a community-based model, it's not just one VC that looks over your shoulders, but you have 400 to 500 people doing the same." Conversely, the community expects to be informed and updated about major developments within the startup or network, often compelling startups to employ dedicated personnel to engage with the community. Managing this relationship can be "worse than having a boss." 


\subsection{Tokenomics}

We define tokenomics as the decisions concerning the design of the token, the underlying blockchain, and the governing entity. Blockchain technology creates opportunities for designing organizations and business models that are valued by founders and startups. In this sense, tokens are multi-purpose instruments that can entail a governing function within an organization. The distribution of this token is accordingly a crucial decision in any ICO.

\subsubsection{Decentralizing organization}

The blockchain creates a transparent ownership structure, which startups leverage to decentralize decision making. Inspired by "The DAO"- (decentralized autonomous organization) one of the earliest attempts for a decentralized autonomous organization - startups use an ICO to distribute voting rights within the network. Under certain protocols, this distribution is necessary to run the network as it ensures that all nodes have a proper incentive to confirm only valid new transactions to the public ledger. However, it is also used as a voting mechanism for decision making within organizations: "We have a distributed autonomous organization. We have a governance document that dictates how you make decisions in our system." This implies that organizations do not hold sole decision making authority other than the collective vote. As a result, token holders can vote to prioritize the development of new product features, advance the business strategy, or make crucial decisions about the organizational structure and personnel.

\subsubsection{Inherent blockchain characteristics}

Startups value inherent blockchain characteristics such as transparency, immutability, openness, and trust. In line with the decentralization of a startup's organizational structure, the blockchain and its underlying token create transparency beyond the voting process: "One of our core values is transparency and honesty. [...] Not only are we telling you that we are honest, but here is the book [referring to the blockchain], it is open, and it's a technology-based thing."
The technology enables startups to be "transparent in how to create value," as all transactions, votes, and contracts are written in the immutable blockchain. Simultaneously, every stakeholder can examine these transactions without further ado and can thereby control or evaluate actions by the startup and community. Fraud or unethical behavior by the fiducially acting startup, which would presumably lead to a withdrawal of investors' money and the subsequent decline of the network, can be identified promptly. As many startups envision creating a global technological standard in their respective field, trust becomes a necessary and important condition, which can be fostered through the distribution of tokens and inherent implications.

\subsubsection{Business model requirements}

Business models can be designed to rely on the blockchain and a distributed token to operate. In these settings, the blockchain not only serves as a technological component of the business model but also incorporates elements that are vital to the business models' value proposition (e.g., for business models that promise to be decentralized). The business model can also be built around the blockchain and the underlying token. This is especially true for decentralized network economies that attempt to replace multi-sided platforms controlled by a single player. In these settings, the platform intermediary is substituted by a self-governing blockchain protocol. The necessity for certain business models was highlighted by one interviewee, who argued: "For some kinds of networks you really need that coin. There is no other option. How will you start your business without the ICO?" This can relate to several features of the business model, such as the token being tied to product usage, executing smart contracts required for the business model, user contributions to a valueadding action for the network, monetary incentives for users, or the token simply being used as a means of payment. Often, startups design the business model, token, and blockchain characteristics and the underlying governing entity in conjunction with each other, where issuing a token becomes a fundamental aspect of starting the project: "You have to have to make sure that you have some sort of usage for the token." These projects are often also open source, and their business models are purely built to financially sustain the maintenance and development of the system. 


\subsection{Personal and ideological drivers}

While funding, community building, and tokenomics refer to advantages and drivers mostly on the organizational level, interviewees also expressed personal and behavioral drivers that motivated them individually to conduct an ICO irrespective of perceived organizational advantages. These drivers can - to a large extent—be labeled as ideologically motivated and resulting from a dissatisfaction with the societal and monetary system.

\subsubsection{Control preferences}

In contrast to equity financing, founders do not need to give up equity to raise funds for ICOs. Although financial incentives play a role, our interviewees preferred the ICO as a mode of financing to keep control rights, especially in light of venture capitalists, who "bleed [the startup] dry" and "dictate terms." Interviewees showed resentment towards traditional financial investors - often due to previous experiences with startups.

"Once you're in bed with VCs then your hands are tied a lot in terms of executive decisions. When things are going well they're good, but when things aren't going so well then you have somebody over your shoulder and that may not be that great for the entrepreneurs."

These resentments can also be linked to the open source and long-term character of blockchain startups mentioned previously, which are generally not well received by venture capitalists. Further, incorporating the community in the governance of a project becomes difficult once a VC investor holds an equity stake in the startup. Interests of the community and venture capitalists can diverge considerably.

\subsubsection{Experimentation}

Interviewees also expressed their personal interest in the technology and general curiosity as a motive to conduct an ICO. As the total number of ICOs is still comparably low, interviewees showed an affinity towards counting themselves among the first to conduct an ICO. Learning and becoming familiar with the technology was another motive mentioned.

\subsubsection{Grassroots decision making}

As previously discussed, the desire to shift authority to the lowest level of the organization is linked to the tendency to use an ICO as a way of decentralizing an organization. The "spirit of the [blockchain] platform" is to distribute authority. Interviewees demonstrated an innate commitment to mirror the distributed element of the blockchain in a democratic decision making model "where people can participate" and "make decisions together in a crowd". As one interviewee stated: "One of my real motivations and passions really was an alternative economic system, a more holistic grassroots, decentralized approach." Interviewees saw themselves as "outliers" in an economic system that is controlled by the few for the many. They regarded blockchain technology as a way of changing the prevailing hegemony of institutions and to create "disruptive innovation" in a collective way.

\subsubsection{Democratization of wealth}

The grassroots approach also translates to the participation in a financial system that is traditionally reserved for institutional investors and high-net-worth individuals only, while being closed to the public:

"Eventually, the wealth of the digital industry can be distributed more democratically. [...] The wealth that is generated would not only end up in the pockets of founders and VCs, but suddenly also in the pockets of all other people who find it interesting."

Resentment towards venture capitalists is also shown in this respect. Interviewees wanted people to have access to a greater quantity and quality of investment opportunities and sought to provide financial freedom with their ICOs.

\subsubsection{Philanthropy}

The blockchain technology is often linked to the empowerment of people and societal progress, as it stands "for freedom of speech, privacy, [and] human rights." "Doing something that was right" and working on something that has "some form of conscious element to it" drives founders to explore opportunities in the blockchain ecosystem. As previously mentioned, many 
projects do not follow a profit motive but instead are interested in "changing the world" and "the progress of humanity" by providing general technological infrastructure to society.

\section{Discussion}

Our evidence shows that entrepreneurs' rationales for pursuing an ICO cover a multifaceted spectrum, which diverges from the single purpose of funding the startup. By not fitting the traditional characteristics and performance criteria of venture capitalists, the blockchain ecosystem - enabled by the sheer opportunities of the underlying technology - simply created its own form of financing. This constitutes a unique phenomenon in entrepreneurial finance. Our findings can be related to several streams of the academic literature.

\subsection{Entrepreneurial finance}

Regarding the literature on entrepreneurial finance, we demonstrate that ICO-funded startups and entrepreneurs show strong resentment towards traditional financing vehicles such as VC. The literature regards VC funding as a desirable goal, with performance-enhancing effects due to value-added services by VCs such as coaching and mentoring (Davila et al. 2003; Sørensen 2007; Croce et al. 2013; Gutmann et al. 2019), benefits from the networks of well-connected VCs, for example to strategic partners (Lindsey 2008), as well as certification (Hsu 2004). These effects increase the likelihood that entrepreneurs will sell equity stakes to reputable investors even at a discount. For ICO-funded firms, entrepreneurs seem to neglect these effects, relating to an overly narrow focus of VCs in their investment choices, the crowd as a substitute for value-added services, the increased time and resources requirements associated with finding VC funding, and divergent objectives in venture development between VCs and founders. While making a distinction from $\mathrm{VC}$ funding, we expected to find links to the nascent research on crowdfunding, which shows similar patterns and characteristics to ICOs. To date, however, the peer-reviewed literature on crowdfunding has barely investigated the different motives and rationales for funding through crowdfunding campaigns. Related to capital structure theory, Walthoff-Borm et al. (2018) found that firms opt for equity crowdfunding when internal funds and debt capacity are exhausted and regard equity crowdfunding as last resort for struggling firms.

For respective founders, an ICO seems to be the path of least resistance in financing their startups. As many ICO-funded startups attach use rights to their issued tokens, these become vouchers for a future service or product. In this sense, the ICO is similar to a product pre-sale which can be associated with financial bootstrapping (Winborg and Landström 2001; Ebben and Johnson 2006). This form of financing is synonymous with internal funds, which are commonly identified as the preferred choice of venture financing, as they have the lowest cost of capital and founders maintain their control rights (Alvarez and Parker 2009). It is however questionable whether this financing truly represents internal funds, as research shows that ICO investors expect a financial return on their investments, which is uncommon for product pre-sales (Fisch et al. 2019). In addition, the SEC strictly classifies tokens as securities if they show specific characteristics irrespective of being assigned use rights.

\subsection{Entrepreneurial decision making and social identity}

We further relate our findings to the literature on entrepreneurial decision making, which has focused only to a limited extent on funding choices. The decision to opt for ICO funding is largely driven by factors that are not considered by academic research. Prior research has rather been concerned with the entrepreneur's perception of the startup, the market, and associated risk (Schwienbacher 2007; Winton and Yerramilli 2008; Alvarez and Parker 2009) or personal traits such as experience, networks, and prior education (Seghers et al. 2012). Instead, our respondents were attracted by the new opportunities and perceived advantages an ICO offers. Economically, financing with an ICO is regarded as an easy vehicle that does not require a heavy resource input but delivers considerable funding outcomes in a hot cryptocurrency market, while also providing valueadded services through the crowd. More importantly, however, the behavioral drivers are new to this stream of literature. Although research on entrepreneurship has shown that entrepreneurs rely on a different set of decision making principles that incorporate their prior experience and education as well as their tastes, preferences, and perceived identity (Sarasvathy 2001; Fauchart and Gruber 2011), ideological drivers have not been incorporated previously. We demonstrate that 
these play a distinct role, as many respondents perceive themselves as "outliers" who do not see themselves represented in the prevailing economic and societal system. Liberal and progressive thinking characterize these individual entrepreneurs who are, in part, guided by the cult surrounding Satoshi Nakamoto, as one cofounder stated: "Always ask yourself: 'what would Satoshi do?" Although many entrepreneurs regard themselves as agents for change (Fauchart and Gruber 2011), our respondents often tried to differentiate themselves from the shiny and glorified Silicon Valley entrepreneurs. They regarded the technology as a way to overturn the prevailing economic system, which they perceived as unfair and skewed to the rich. Especially in the context of entrepreneurial finance, many saw the VC industry as the only winner in innovation and entrepreneurship, which drove them towards ICO funding.

Based on these findings, links can be drawn to relevant theories that may explain some of our findings, in particular social identity theory (Tajfel and Turner 1979; Ashforth and Mael 1989), which has lately received attention in entrepreneurship research (Fauchart and Gruber 2011; Gruber and MacMillan 2017). As individuals self-categorize into different social groups and thereby create distinct social identities that serve as schemes of social orientation, we can interpret their decisions based on the cognitive frames and norms used within these contexts. Fauchart and Gruber (2011) propose three types of founder identities, which help scholars in understanding entrepreneurial behavior: Darwinian (focused on financial success), communitarian (focused on contributing to communities), and missionary (focused on societal change). Prior research has linked entrepreneur's identities, among other factors, to internationalization decisions (Bolzani and Der Foo 2018), responses to adversity (Powell and Baker 2014), organizational inertia and flexibility (Zuzul and Tripsas 2019), and engagement in environmental entrepreneurship (York et al. 2016). We can extend these findings and show that the funding decision for ICO-funded startups is largely driven by strong missionary identities of entrepreneurs merged with a focus on community engagement. We contemplate that this drive is historically rooted in the blockchain community, which came into existence in 2009 after the financial crisis and promised a new economic and financial system based on blockchain technology, which, by itself, can be seen as an ideological movement. Further, cryptocurrencies have often been linked to money laundering, drug trafficking, and illegal activities in general. This created a distinct separation between the blockchain ecosystem and the mainstream entrepreneurship as well as capital markets. Respondents saw themselves as being excluded from this system either through geographic separation, lack of commercialization possibilities, or lack of personal merit (Cosh et al. 2009). This "Us vs. Them" sentiment leads to startups in the blockchain ecosystem showing a strong attachment to their mission and underlying values, which are also embodied by the technology itself and eventually in the funding choice.

It is crucial to understand that these ideological drivers are shared by the entrepreneur's relevant social world, which provides considerable resources and capabilities to the startup (Gruber and MacMillan 2017). Entrepreneurs in the blockchain ecosystem see different non-traditional pathways to value creation, which are embedded in the ecosystem and show signs of institutionalization, as one respondent said: "It was the thing to do at the time." The ICO can be regarded as a legitimacy threshold in the development of a blockchain-based startup. Especially young ventures, who depend on external funding, need to be perceived as legitimate by investors and therefore adopt category-specific processes and structures. Considering that the audience in crowd-funded projects, such as ICOs, has different beliefs, norms, and rules for assessing a venture compared to traditional funding sources (Fisch et al. 2019), the entrepreneur's identity is oftentimes a reflection of underlying routines and values and is imprinted in entrepreneurial behavior (Navis and Glynn 2011; Fisher et al. 2016).

\subsection{Digital entrepreneurship}

Related to the nascent stream of digital entrepreneurship (Nambisan 2017), we find evidence that the technology enables startups to create new organizational forms and business models governed by the underlying token. These forms and models are distinct from traditional governance and incentive mechanisms, reflecting not only a communitarian identity but also the nature as open source projects (von Krogh and von Hippel 
2006; O’Mahony and Ferraro 2007), which has been linked to entrepreneurial identity and motivation (Greul et al. 2018). The blockchain technology enables new venture creation and thereby constitutes a substitute for traditional funding alternatives in terms of funding, but also in terms of feedback through a community-based approach (Ahlstrom et al. 2018). We can relate these findings to von Briel et al. (2018) and confirm that digital technologies can provide a substitutive mechanism to startups by replacing traditional resources or resource dependencies in traditional pathways to entrepreneurship. Relating to Nambisan et al. (2019) the blockchain technology shows the potential to transform the degree of openness in entrepreneurship by increasing the variance in participants and outcomes.

In this regard, the blockchain technology further redefines the boundaries of agency as it can incorporate a diverse range of stakeholders, incentivize them and democratize decision making in a startup, therefore leading to community building and a more collective way of engaging in entrepreneurship. ICO-funded startups perceive the community and crowd as a relevant factor in pursuing an ICO. Incentivized by the organizational structure and a potential appreciation of the underlying token, investors feel more committed to participating in the development of the startup and are likely to serve as advisors and beta testers. Startups thereby have a unique tool to incentivize the development of multi-sided platforms and kick off network effects without spending on promotion. This is also in line with our argument for tokenomics, which suggests that technological characteristics of the blockchain and the underlying design of the technology and token drive the choice of an ICO. Being governed by the blockchain and the underlying token, entrepreneurs can relax control and draw on the blockchain's capacity to foster exchange and value creation (Nambisan et al. 2018; von Briel et al. 2018). These technological shifts go hand in hand with the abovementioned social identity of the founders and entrepreneurs: community building, shared value creation and a joint mission and belief system shape the economic and sociotechnical interactions between founders, community, and technology. The ICO becomes a manifestation of the underlying technology, but also of the social ecosystem. Entrepreneurs are able to draw on the reputation of the blockchain and incorporate inherent characteristics such as trust, openness and immutability in their self and their startup (Nambisan et al. 2018).

Further, elements of a distributed autonomous organization can frequently be found among motives of entrepreneurs to conduct an ICO. This poses not only new challenges but also opportunities to corporate governance and organizational theory (Wareham et al. 2014; Cumming et al. 2019). By issuing tokens and decentralizing their organizations, startups can create unique structures that are self-governed and selfregulated through the economic incentive generated by the underlying token.

\subsection{Limitations and avenues for future research}

We employed a qualitative and inductive research approach that mainly relied on semi-structured interviews. This approach brings with it issues of external validity and reliability. Although we took measures to reduce interview bias, such as conducting pilot interviews, avoiding leading questions, and giving interviewees the chance to sum up their arguments, we cannot undoubtedly guarantee that our data collection process is reliable. Regarding our approach to data analysis, we have strong confidence that the rigorous and disciplined process yielded credible interpretations of the data. Furthermore, we are confident that we reached a considerable degree of data saturation. However, as some scholars (e.g., Blaseg 2018) have identified more than 1000 ICOs in their samples, our sample size shrinks to a mere $3 \%$ of the whole population. In this regard, larger samples and surveys should validate our findings.

As ICOs constitute an as of yet unexplored and nascent field of inquiry, our findings need to be complemented by future research in this area to provide a broader context and shape our understanding of ICOs. First, our study demonstrates that funding is considered a primary motive to conduct an ICO. A better understanding of the factors that determine the amount of funding is needed, and attention should be devoted to moral hazard issues once startups raise more funds than needed. In this context, future research could also explore what control mechanisms for investors can be established and how ICOs can be regulated. Moreover, during our interviews, we debated whether ICOs were complementary to or a substitute for venture capital. 
Future studies should attempt to answer this question and dive into the effect that ICOs have on the VC industry. Particularly interesting is the value-added aspect in this context. As VCs add value to their portfolio companies by providing smart capital and thus nonfinancial benefits to help their portfolio companies create and capture value (Sørensen 2007; Croce et al. 2013; Gutmann 2019), future research could investigate whether value-added services are truly provided by the ICO community. Future longitudinal studies could explore the long-term success of ICO-funded companies compared to VC-funded startups and investigate at which stage of the startup are ICOs best employed.

Second, the community building aspect emerged as an impetus to conduct an ICO. More research is needed to understand how startups engage with their communities, which engagement model is the most effective, and especially how this engagement affects ICO performance. Furthermore, some ICOs were used to sell and distribute tokens with the aim of sparking network effects. More research on this topic should be undertaken before the association of token sales and distribution with network effects can be better understood.

Third, as tokenomics - the decisions concerning the design of the token, the underlying blockchain, and the governing entity-emerged as a main reason to conduct an ICO, further research should be undertaken to investigate this dimension. Several questions remain unanswered in terms of the different token designs used in ICOs. Moreover, the emergence of new organizational forms such as the DAO calls for future elaboration, for instance, how does the DAO affect our understanding of what constitutes an organization and how we think about governance in both a for-profit and a non-profit context (Wareham et al. 2014; Nambisan et al. 2018). We further establish an interplay between a startup's funding choice and its business model. As many blockchain startups' business models rely on an underlying token to operate, issuing the respective token is indispensable. This ties the funding choice to the business model. Though scholars have established a link between corporate strategy and capital structure (Barton and Gordon 1988; Kochhar and Hitt 1998), a relationship between business model and financing is something not yet recognized in the academic literature. There is a need to investigate whether this interplay can be extended beyond solely blockchain applications as the ICO space matures.

\section{Conclusion}

This paper investigated the different economic and behavioral factors that motivate entrepreneurs to fund their startup operations with ICOs. ICOs have become a mainstream source of capital, especially for blockchain startups, and have driven billions of dollars into the blockchain ecosystem while challenging traditional funding vehicles such as BA or VC investments. By conducting in-depth interviews with C-level managers or founders of ICOfunded startups, our rigorous analysis revealed four dimensions that have an impact on the decision to undertake an ICO: funding, community building, tokenomics, and personal and ideological drivers. We contribute to the literature on entrepreneurial finance by furthering the understanding of this new source of finance and to the literature on entrepreneurial decision making by providing qualitative insights into the funding choice of entrepreneurs. We show that entrepreneurs' identity, manifested in behavioral and ideological drivers, is a distinct driver in opting for an ICO. Our contribution is relevant for both practitioners in the financial industry as well as for regulators attempting to discern the nascent funding vehicle that an ICO represents.

Acknowledgments We wish to thank Tom Vanacker and the two anonymous reviewers who spurred the development of this research project. We further thank the participants of the 6th Crowdinvesting Symposium at the Max Planck Institute for Innovation and Competition in Munich, Germany, for their valuable feedback. We would also like to thank Alexander P. Müller, Dmitri Boreiko, Himani Singh, and Eirikur Høgni Sanderson for their support.

Funding Information Open Access funding provided by Projekt DEAL.

Open Access This article is licensed under a Creative Commons Attribution 4.0 International License, which permits use, sharing, adaptation, distribution and reproduction in any medium or format, as long as you give appropriate credit to the original author(s) and the source, provide a link to the Creative Commons licence, and indicate if changes were made. The images or other third party material in this article are included in the article's Creative Commons licence, unless indicated otherwise in a credit line to the material. If material is not included in the article's Creative Commons licence and your intended use is not permitted by statutory regulation or exceeds the permitted use, you will need to obtain permission directly from the copyright holder. To view a copy of this licence, visit http://creativecommons.org/licenses/by/4.0/. 


\section{Appendix}

Dimension Themes $\quad$ Representative quotes

Funding

Unlocking capital of individual "I think the biggest advantage is tapping a completely new set of investors that do not have the investors globally

Creating liquidity agenda, that traditional investors have."

"The best thing is that it is open for every investor to invest in because we know that many projects are closed to investors."

"Before, nobody gave a shit about startups in a small country.

But now Americans and all the big countries are calling us to help them."

"It really comes down to this new way to fund or finance companies. It unlocks capital."

"It's like regular crowdfunding, with token sales, you remove the need for paying their fees. So there are platforms taking a piece of the raise that you do.

And ICOs are a version of that, but on steroids."

"So everything can become tradable if you tokenize it."

"The whole difference that will change this industry forever is that your investment can be traded right away. Before, when you invested in a startup, the exit was in five years, and today it's in one week. It's steroids for the whole industry."

"If I create a token for the fund, then it is tradable and suddenly it creates an innovation in an asset class which used to be totally static."

"We value the token because of the utility function that it provides. It does provide a straightforward way for a private organization to being shareholders or stakeholders - to enter and to exit."

Ease of funding

"You can do fundraising with Sequoia or with the incubators in five years, in three years. I do it overnight. So let us see who is faster."

"I mean, it's definitely easy money. You do not have to do as much as you would have to do with, like, if you are looking for seed investors. The problem is a lot of the projects that are ICOing have recognized that and are just flimsy bullshit that would never get funded anyways. But in the ICO space they can get a shit ton of money."

"You could actually launch an ICO very easily with like minimal efforts and resources."

"That is akin to web shops. And basically starting an ICO is much like starting a web shop, anybody can do that."

"Another big advantage is that most ways of raising money today outside of ICOs have large barriers to entry. Finding an angel investor is very hard, but about anyone can go through the steps and issue an ICO."

"I think the really exciting thing for me that it was accessible to anybody. Anybody with an idea who can put together a sales pitch can run an ICO."

Hot market

"And then I said, well, 'Here comes the ICO boom. Let us do an ICO."”

"It was like a big hot thing. It was the thing to do at the time, right?"

"We saw groups that did not have the technology and knowledge that we have. Some of them just had a white paper but they raised millions and millions. We started to study if we can do the same."

"So as crypto hobbyists, my co-founder and I have been seeing the ICO market blowing up. The straw that really made it: We have been thinking about an ICO, we have sketched it out internally, we thought about it, and then when we saw [...] the bad token, sell 30 million dollars in 30 seconds, or whatever that was. We thought: 'Yes, we are going to do this!"”

"But that was the way you'd raise funds if you had a crypto project. That's how you would do that."

Lack of other funding options

"If you want to develop your project for three to four years, even five years before you have your breakthrough, most VCs cannot hang on that long."

"There was no way we would have raised money with a VC's to get us operational."

"Venture Capitalist were not actually looking into crypto. I'm talking about 2014. No one knew what crypto is, if we talked with anyone about Bitcoin, we'd need to start with the very discussion about why it is not a Ponzi-scheme, what Bitcoin is, what we call blockchain."

"Most open source projects are just kind of a labour of love by somebody who does them and does not get paid and it's numb. But we have open source projects now that never would happen without funding."

"We asked around some VC's firms, plenty of times, but they would not do a deal with us." 


Dimension $\quad$ Themes $\quad$ Representative quotes

Community building
Validating the market

Generating buzz

Kicking off network effect

Wisdom of the crowd
"Simply because they [VC's] lack the understanding of how blockchain technology works. Even today, still, they do not understand it."

"We had been talking to VCs. Their major interest is seeing a working product before they invest. And that has been the case all along

"It's not the rapid return on investment type model that equity investors are looking for because this is the kind of things they look at it and say 'too much risk, too much unknown, too much uncertainty, and too long before we can even think about getting our money back. It does not make sense for us to invest in something like that."

"I think the ICO space not only emerged but got as big as it did as fast as it did because crypto developers could not access traditional venture capital. They were shut out.

There was an immediate prejudice against crypto currencies from all traditional financial institutions."

"I think what's happening now is a very good idea, which very early stage themes can use as a mechanism to get a reasonable amount of funds to get the project flow. It works really well."

"Making it easier for people to get funds to build their ideas rather then traditional funding routes where you have to know a lot."

"The biggest reason was funding of an idea, that was the biggest reason. Nothing else."

"Because, well, mostly because we were not sure how this will go. So, you are basically testing the market by doing that."

"You get to see how interested the market is. So it is a little bit of a market assessment. Checking out the demand."

"What we had to do, we literally had to create a market price for the product. So there had to be a sale and there had to be an exchange for it to be useable, because we needed a monetary basis for the branded tokens that we made. So that sort of helped do that."

"When we produce a product, they operate as beta testers."

We were really just testing the marketplace to see if there are future customers that are willing to pay for a blockchain. We considered it like a Kickstarter project, which tries to sell watches on the market."

"You create a huge marketing group that will help you launch the project."

"It has very little to do with blockchain innovation and a whole lot to do with getting the public's attention very efficiently, cost efficiently."

"So the ICO is an excellent way to create that level of excitement and invention."

"The advantage of the token sale was to drive interest in [our product], to gain investors and to build the ecosystem which requires a distribution of the tokens to the public."

"We wanted to create the network effect we were looking for. It was part of the deal of doing a new thing."

"It's also a way to jumpstart the internal mechanism of the product right off the bat."

"The token is a way to incentivize the user."

"The value of the cryptocurrency is tied to the network effects and you only get a network effect if lots of people are holding the cryptocurrency."

"In our understanding, the token sale brings a lot of people on the platform."

"There was the question of chicken-or-egg, which is applicable to any marketplace application where you need to bring supply and demand together. So how do you do the magic circle with who comes first? And how do you create this network? [...] We wanted to create the network effect we were looking for. It was part of the deal of doing a new thing."

Creating a loyal customer basis "By holding tokens in our services, you have advantageous access to services. So this is like your frequent flyer miles on an airline."

"If it's a B2C product, you can bind end customers differently. The customer has a feeling for the product. The customer loyalty is so strong, that they are even willing to pay for their loyalty."

"Today that is what you are looking for: people who are totally engaged to your vision, who love your products, or love that what the team is capable of doing."

"We benefit from the fact that a lot of these people are highly educated, technically adept, clued in the news, and they bring all that intelligence into the selection process."

"For us, it was more about generating the community and really testing the hypothesis of the wisdom of the crowd." 
Tokenomics

Decentralizing organization

Inherent blockchain characteristics

Business model requirements

Personal and ideological drivers
"It has been really helpful to have a community. Having this regular feedback has been really helpful for guidance in developing our product and our strategy."

"I think the community aspect is more valuable then the funding."

"The new crypto investors are similar to VCs. They are new kinds of investors, who also have a network and can support us. I think it's equivalent to a VC's."

"In a community-based model, it's not just one VC's that looks over your shoulders, but you have 400 to 500 people doing the same."

"However, when you have a community of a couple of thousand people asking you everyday things, it's a big push. It's worse then having a boss. I'm not kidding."

"It was one of the earliest DAOs - a decentralized autonomous organization. We had a unique protocol for decision making within the community and basically the legal entity was just the execution arm for the community."

"So, in a nutshell: If you have tokens, you can be part of the ecosystem for blockchain governance."

"Our intention is to exit and have it fully decentralized within three or four years."

"Constructing an ecosystem that will run on its own in the distributed autonomous fashion requires a token, because the protocol has to be able to pay people to run it."

"And so we, we are a distributed autonomous protocol. And thus we have a distributed autonomous organization. We have a governance document that dictates how you make decisions in our system."

"That was exactly the thing we wanted to do. We wanted to make one DAO were token holders vote."

"It's not so much decentralization, which is talked a lot about. It's more about transparency, building a reputation on transparencies. This is actually where the main value is coming from."

"One of our core values is transparency and honesty. [...] Not only are we telling you that we are honest, but here is the book [referring to the blockchain], it is open, and it's a technology-based thing"

"That vote is recorded on the blockchain, so it is absolutely immutable and it is absolutely transparent. Anybody who can read a blockchain explorer can see the results of that vote, so it makes it very, very attractive to people who might not trust a more conventional voting mechanism.."

"You have to have to make sure that you have some sort of usage for the token. Especially for the company that is not a traditional crypto company, you have to see whether or not it is worth the hassle."

"If you want to substitute a platform economy with a network economy, and really set-up a decentralized network economy for certain industries then I believe in the power of an ICO."

"In blockchain based solutions and open standards in which tokens really make sense, an ICO also makes sense."

"You need this token in order for the blockchain to operate."

"Yes, for some kinds of networks you really need that coin. There is no other option. How will you start your business without the ICO?"

"So the biggest advantage is that you are not giving away equity from a financial perspective. You're not giving away control rights. You collect money without giving away something."

"Once you are in bed with VC's then your hands are tied a lot in terms of executive decisions and when things are going well it's good, but when things aren't going so well then you have somebody over your shoulder and that may not be that great for the entrepreneurs."

"I own the company and I do not have to answer to anyone at this point."

"I do not like giving away equity. Especially not to some VC's."

"Because of the previous company that our founder had, he knew the VC's bleeds you dry, right? They dictate terms. Very rarely the founder's incentives and VC's incentives align."

"We did not really like the idea of having one, either one person or a few people, coming with money that would then dictate how the business was going to go."

Experiment
"Why we did the ICO? Because we were curious."

"I thought it'd be a really neat experiment."

"It's an experiment. We wanted to get familiar with the technology. See if can we do it."

"So we do the ICO, because we basically wanted to test the waters." 


Dimension Themes $\quad$ Representative quotes

Grassroots decision making

Democratization of wealth

Philanthropy
"We were literally the first people who did this and then were all the projects that were sort of experimenting along the way."

"One of my real motivations and passions really was an alternative economic system. The more holistic grassroots, decentralized approach."

"I just felt that more in the spirit of the platform and the philosophy behind it because it would be more decentralized. You'll need to be more grassroots, it would be, you know, more user and community oriented as opposed to corporate. So that was really the motivation"

"I do strongly believe that we are entering a new age. We just actually picked our roots as humans that we create value together in a social way."

"We have a community of outliers who make a decision together in a crowd. And I think the opportunity for disruptive change is therefore much greater."

"We wanted to show a model where it's much more democratic where people can participate in that mechanism to run that operation and control it."

"Eventually, the wealth of the digital industry can be distributed more democratically. To put it short: The wealth that is generated would not only end up in the pockets of founders and VCs, but suddenly also in the pockets of all other people who find it interesting."

"To put the power of financial freedom back into the hands of the normal everyday people to have a form of currency that could not be manipulated by the whims of a few people. So for me, the idea of cryptocurrency was a breath of fresh air, it was the third great awakening - how I call it."

"Somebody who is interested in technology, could throw 50 dollars at it and see if it works."

"I believe that the way how to finance startups, you are offering hope, that it can be financed by everyone and not overexposing him to large sums."

"It was interest in the progress of humanity that drove me to cryptocurrencies."

"We're trying to change the world. So open source is great. We do not need a profit motive."

"I really believe in the potential of the technology to change the way the world works. So I wanted to be able to be a part of that process."

"So, a motivator for me was primarily trying to do something that was right."

"Well, I would say that the motivation of myself and many of the people in our company is very idealistic."

"What we are doing is very philosophical. I mean, we are approaching this in a philosophical point of view. And so for us, it is a bit unusual. The business model, and the reason behind it."

"I do not work on anything that does not have some form of social conscious element to it."

\section{References}

Adhami, S., Giudici, G., \& Martinazzi, S. (2018). Why do businesses go crypto? An empirical analysis of initial coin offerings. Journal of Economics and Business. https://doi. org/10.2139/ssrn.3046209.

Ahlstrom, D., Cumming, D. J., \& Vismara, S. (2018). New methods of entrepreneurial firm financing: Fintech, crowdfunding and corporate governance implications. Corporate Governance: An International Review, 26(5), 310-313. https://doi.org/10.1111/corg.12258.

Aldrich, H. E. (1999). Organizations evolving. London: Sage Publications.

Alvarez, S. A., \& Parker, S. C. (2009). Emerging firms and the allocation of control rights: A Bayesian approach. Academy of Management Review, 34(2), 209-227. https://doi. org/10.5465/AMR.2009.36982616.

Amsden, R., \& Schweizer, D. (2018). Are blockchain crowdsales the new "gold rush"? Success determinants of initial coin offerings. SSRN Electronic Journal. https://doi.org/10.2139 /ssrn.3163849.

Ashforth, B. E., \& Mael, F. (1989). Social identity theory and the organization. Academy of Management Review, 14(1), 2039. https://doi.org/10.5465/amr.1989.4278999.

Baron, R. A. (2008). The role of affect in the entrepreneurial process. Academy of Management Review, 33(2), 328-340. https://doi.org/10.5465/AMR.2008.31193166.

Barton, S. L., \& Gordon, P. J. (1988). Corporate strategy and capital structure. Strategic Management Journal, 9(6), 623632. https://doi.org/10.1002/smj.4250090608.

Belleflamme, P., Lambert, T., \& Schwienbacher, A. (2010). Crowdfunding: An industrial organization perspective. In Prepared for the workshop Digital Business Models. Understanding Strategies 10.1.1.416.4643.

Blaseg, D. (2018). Dynamics of voluntary disclosure in the unregulated market for initial coin offering. SSRN electronic journal. Retrieved from https://ssrn.com/abstract=3207641

Block, J. H., Colombo, M. G., Cumming, D. J., \& Vismara, S. (2018a). New players in entrepreneurial finance and why 
they are there. Small Business Economics, 50(2), 239-250. https://doi.org/10.1007/s11187-016-9826-6.

Block, J., Hornuf, L., \& Moritz, A. (2018b). Which updates during an equity crowdfunding campaign increase crowd participation? Small Business Economics, 50(1), 3-27. https://doi. org/10.1007/s11187-017-9876-4.

Bolzani, D., \& Der Foo, M. (2018). The "why" of international entrepreneurship: Uncovering entrepreneurs' personal values. Small Business Economics, 51(3), 639-666. https://doi.org/10.1007/s11187-017-9945-8.

Boreiko, D., \& Sahdev, N. (2018). To ICO or not to ICO Empirical analysis of initial coin offerings and token sales. SSRN electronic journal. Retrieved from https://ssrn. com/abstract $=3209180$

Busenitz, L. W., \& Barney, J. B. (1997). Differences between entrepreneurs and managers in large organizations: Biases and heuristics in strategic decision-making. Journal of Business Venturing, 12(1), 9-30. https://doi.org/10.1016 /S0883-9026(96)00003-1.

Buterin, V. (2014). Ethereum: A next-generation cryptocurrency and decentralized application platform. GitHub. Retrieved from https://github.com/ethereum/wiki/wiki/White-Paper

Buterin, V. (2015). Visions, part 1: The value of blockchain technology. Retrieved from https://blog.ethereum.org/2015 /04/13/visions-part-1-the-value-of-blockchain-technology/

Cachin, C. (2016). Architecture of the hyperledger blockchain fabric. IBM Research.

Carpenter, R. E., \& Petersen, B. C. (2002). Is the growth of small firms constrained by finance? The Review of Economics and Statistics, 84(2), 298-309.

Cassar, G. (2004). The financing of business start-ups. Journal of Business Venturing, 19(2), 261-283. https://doi.org/10.1016 /S0883-9026(03)00029-6.

Catalini, C., \& Gans, J. S. (2018). Initial coin offerings and the value of crypto tokens (MIT Sloan School Working Paper 5347-18). Retrieved from https://ssrn. com/abstract $=3137213$

Chaganti, R., DeCarolis, D., \& Deeds, D. (1995). Predictors of capital structure in small ventures. Entrepreneurship Theory and Practice, 20(2), 7-18. https://doi.org/10.1177 $/ 104225879602000202$.

Chandler, G. N., \& Hanks, S. H. (1998). An examination of the substitutability of founders human and financial capital in emerging business ventures. Journal of Business Venturing, 13(5), 353-369. https://doi.org/10.1016/S0883-9026(97 )00034-7.

Chen, Y. (2018). Blockchain tokens and the potential democratization of entrepreneurship and innovation. Business Horizons, 61(4), 567-575.

Cohen, W. M., \& Levinthal, D. A. (1990). Absorptive capacity: A new perspective on learning and innovation. Administrative Science Quarterly, 35(1), 128. https://doi.org/10.2307 12393553.

Colombo, M. G., \& Grilli, L. (2007). Funding gaps? Access to bank loans by high-tech start-ups. Small Business Economics. https://doi.org/10.1007/s11187-005-4067-0.

Conley, J. P. (2017). Blockchain and the economics of cryptotokens and initial coin offerings. Vanderbilt University Department of Economics Working Papers. Retrieved from http://www.accessecon.com/Pubs/VUECON/VUECON-1700008.pdf
Corbin, J. M., \& Strauss, A. L. (1998). Basics of qualitative research: Techniques and procedures for developing grounded theory (fourth edi). Los Angeles, London, New Delhi, Singapore, Washington DC, Boston: SAGE Publications.

Corley, K. G., \& Gioia, D. A. (2004). Identity ambiguity and change in the wake of a corporate spin-off. Administrative Science Quarterly, 173-208(2 ER). https://doi.org/10.2307/4131471.

Cosh, A., Cumming, D., \& Hughes, A. (2009). Outside enterpreneurial capital. The Economic Journal, 119(540), 1494-1533. https://doi.org/10.1111/j.14680297.2009.02270.x.

Croce, A., Martí, J., \& Murtinu, S. (2013). The impact of venture capital on the productivity growth of European entrepreneurial firms: "Screening" or "value added" effect? Journal of Business Venturing, 28, 489-510. https://doi.org/10.1016/j. jbusvent.2012.06.001.

Crosby, M., Nachiappan, Pattanayak, P., Verma, S., \& Kalyanaraman, V. (2016). BlockChain technology: Beyond Bitcoin. Applied Innovation Review, 2(6-10), 71.

Cumming, D., \& Groh, A. P. (2018). Entrepreneurial finance: Unifying themes and future directions. Journal of Corporate Finance, 50, 538-555.

Cumming, D. J., Vanacker, T., \& Zahra, S. A. (2019). Equity crowdfunding and governance: toward an integrative model and research agenda. Academy of Management Perspectives. https://doi.org/10.5465/amp.2017.0208.

Cyert, R. M., \& DeGroot, M. H. (1987). Bayesian analysis and uncertainty in economic theory. Rowman \& Littlefield.

Davila, A., Foster, G., \& Gupta, M. (2003). Venture capital financing and the growth of startup firms. Journal of Business Venturing, 18(6), 689-708. https://doi.org/10.1016/S08839026(02)00127-1.

Degryse, H., de Goeij, P., \& Kappert, P. (2012). The impact of firm and industry characteristics on small firms' capital structure. Small Business Economics, 38(4), 431-447. https://doi. org/10.1007/s11187-010-9281-8.

Drobetz, W., Momtaz, P. P., \& Schröder, H. (2019). Investor sentiment and initial coin offerings. The Journal of Alternative Investments, 21(4), 41-55.

Drover, W., Busenitz, L., Matusik, S., Townsend, D., Anglin, A., \& Dushnitsky, G. (2017). A review and road map of entrepreneurial equity financing research. Journal of Management, 43(6), 1820-1853. https://doi.org/10.1177 /0149206317690584.

Ebben, J., \& Johnson, A. (2006). Bootstrapping in small firms: An empirical analysis of change over time. Journal of Business Venturing, 21(6), 851-865. https://doi.org/10.1016/j. jbusvent.2005.06.007.

Eckhardt, J. T., Shane, S., \& Delmar, F. (2006). Multistage selection and the financing of new ventures. Management Science, 52(2), 220-232. https://doi.org/10.1287/mnsc.1050.0478.

Eisenhardt, K. M. (1989). Building theories from case study research. Academy of Management Review, 14(4), 532-550. https://doi.org/10.5465/AMR.1989.4308385.

Estrin, S., Gozman, D., \& Khavul, S. (2018). The evolution and adoption of equity crowdfunding: Entrepreneur and investor entry into a new market. Small Business Economics, 51(2), 425-439. https://doi.org/10.1007/s11187-018-0009-5.

Fauchart, E., \& Gruber, M. (2011). Darwinians, communitarians, and missionaries: The role of founder identity in 
entrepreneurship. Academy of Management Journal, 54(5), 935-957. https://doi.org/10.5465/amj.2009.0211.

Fisch, C. (2019). Initial coin offerings (ICOs) to finance new ventures. Journal of Business Venturing, 34(1), 1-22. https://doi.org/10.1016/j.jbusvent.2018.09.007.

Fisch, C., Masiak, C., Vismara, S., \& Block, J. (2019). Motives and profiles of ICO investors. Journal of Business Research. https://doi.org/10.1016/j.jbusres.2019.07.036.

Fisher, G., Kotha, S., \& Lahiri, A. (2016). Changing with the times: An integrated view of identity, legitimacy, and new venture life cycles. Academy of Management Review, 41(3), 383-409. https://doi.org/10.5465/amr.2013.0496.

Gartner, W. B., Frid, C. J., \& Alexander, J. C. (2012). Financing the emerging firm. Small Business Economics, 39(3), 745761. https://doi.org/10.1007/s11187-011-9359-y.

Gerber, E. M., Hui, J. S., \& Kuo, P-Y. (2012). Crowdfunding: Why people are motivated to post and fund projects on crowdfunding platforms. Position Paper at CSCW 2012 DIST Workshop, 10. https://doi.org/10.1145/2530540

Gioia, D. A., \& Chittipeddi, K. (1991). Sensemaking and sensegiving in strategic change. Strategic Management Journal, 12(6), 433-448. https://doi.org/10.1002 /smj.4250120604.

Gioia, D. A., Corley, K. G., \& Hamilton, A. L. (2013). Seeking qualitative rigor in inductive research: Notes on the Gioia method. Organizational Research Methods, 16(1), 15-31. https://doi.org/10.1016/j.chb.2013.04.024.

Gioia, D. A., Thomas, J. B., Clark, S. M., \& Chittipeddi, K. (1994). Symbolism and strategic change in academia: The dynamics of sensemaking and influence. Organization Science, 5(3), 363-383. https://doi.org/10.1287/orsc.5.3.363.

Glaser, B. G., \& Strauss, A. L. (1967). The discovery of grounded theory. International Journal of Qualitative Methods. https://doi.org/10.2307/588533.

Greul, A., West, J., \& Bock, S. (2018). Open at birth? Why new firms do (or don't) use open innovation. Strategic Entrepreneurship Journal, 12(3), 392-420. https://oi. org/10.1002/sej.1282.

Gruber, M., \& MacMillan, I. C. (2017). Entrepreneurial behavior: A reconceptualization and extension based on identity theory. Strategic Entrepreneurship Journal, 11(3), 271-286. https://doi.org/10.1002/sej.1262.

Gutmann, T. (2019). Harmonizing corporate venturing modes: An integrative review and research agenda. Management Review Quarterly, 69(2), 121-157. https://doi.org/10.1007/s11301-018$0148-4$.

Gutmann, T., Schmeiss, J., \& Stubner, S. (2019). Unmasking smart capital: How corporate venture capital firms configure value-adding services. Research-Technology Management, 62(4), 27-36.

Howell, S. T., Niessner, M., \& Yermack, D. (2018). Initial coin offerings: Financing growth with cryptocurrency token sales. SSRN electronic journal. Retrieved from http://ssrn. com/abstract_id=3201259

Hsu, D. H. (2004). What do entrepreneurs pay for venture capital affiliation? The Journal of Finance, 59(4), 1805-1844. https://doi.org/10.1111/j.1540-6261.2004.00680.x.

Huang, W., Meoli, M., \& Vismara, S. (2019). The geography of initial coin offerings. Small Business Economics. https://doi. org/10.1007/s11187-019-00135-y.
Kher, R., Terjesen, S., \& Liu, C. (2020). Blockchain, Bitcoin, and ICOs: a review and research agenda. Small Business Economics. https://doi.org/10.1007/s11187-019-00286-y.

Kochhar, R., \& Hitt, M. A. (1998). Linking corporate strategy to capital structure: Diversification strategy, type and source of financing. Strategic Management Journal, 19(6), 601-610.

Koudstaal, M., Sloof, R., \& van Praag, M. (2018). Entrepreneurs: Intuitive or contemplative decision-makers? Small Business Economics. https://doi.org/10.1007/s11187-018-0109-2.

Kvale, S., \& Brinkmann, S. (2009). Interview: Learning the craft of qualitative research interviewing. SAGE Publications.

Lincoln, Y. S., \& Guba, E. G. (1985). Naturalistic inquiry. Sage Publications. https://doi.org/10.1177/1473325006070288.

Lindsey, L. (2008). Blurring firm boundaries: The role of venture capital in strategic alliances. Journal of Finance, 63(3), 1137-1168. https://doi.org/10.1111/j.15406261.2008.01354.x.

Locke, K. (2001). Grounded theory in management research. Thousand Oaks: SAGE Publications.

Lofland, J., \& Lofland, L. H. (1971). Analyzing social settings. Belmont: Wadsworth. https://doi.org/10.1177 /089124196025003006.

Makadok, R., Burton, R., \& Barney, J. (2018). A practical guide for making theory contributions in strategic management. Strategic Management Journal, 39, 1530-1545. https:/doi. org/10.1002/smj.2789.

Markowska, M., Grichnik, D., Brinckmann, J., \& Kapsa, D. (2018). Strategic orientations of nascent entrepreneurs: Antecedents of prediction and risk orientation. Small Business Economics, 53, 859-878. https://doi.org/10.1007 /s11187-018-0107-4.

Masiak, C., Block, J. H., Masiak, T., Neuenkirch, M., \& Pielen, K. N. (2019). Initial coin offerings (ICOs): Market cycles and relationship with bitcoin and ether. Small Business Economics, 1-19.

Mattila, J. (2016). The blockchain phenomenon the disruptive potential of distributed consensus architectures. ETLA Working Papers, 38(38), 26. https://doi.org/10.1098 /rsnr.2016.0036.

McGrath, R. G. (1999). Falling forward: Real options reasoning and entrepreneurial failure. Academy of Management Review, 24(1), 13-30.

McKenny, A. F., Allison, T. H., Ketchen, D. J., Short, J. C., \& Ireland, D. (2017). How should crowdfunding research evolve? A survey of the entrepreneurship theory and practice editorial board. Entrepreneurship Theory and Practice, 41(2), 291-304.

Miozzo, M., \& DiVito, L. (2018). Productive opportunities, uncertainty, and science-based firm emergence. Small Business Economics. https://doi.org/10.1007/s11187-018-0033-5.

Momtaz, P. P. (2018). Initial coin offerings. SSRN electronic journal. Retrieved from https://ssrn.com/abstract=3166709

Moritz, A., \& Block, J. H. (2016). Crowdfunding: A literature review and research directions. crowdfunding in Europe. Cham: Springer. https://doi.org/10.2139/ssrn.2554444.

Myers, S. C. (1984). The capital structure puzzle. The Journal of Finance. https://doi.org/10.1111/j.1540-6261.1984.tb03646.x.

Myers, S. C., \& Majluf, N. S. (1984). Corporate financing and investment decisions when firms have information that investors do not have. Journal of Financial Economics, 13(2), 187-221. https://doi.org/10.1016/0304-405X(84)90023-0. 
Nakamoto, S. (2008). Bitcoin: A peer-to-peer electronic cash system. https://doi.org/10.1007/s10838-008-9062-0.

Nambisan, S. (2017). Digital entrepreneurship: Toward a digital technology perspective of entrepreneurship. Entrepreneurship: Theory and Practice, 41(6), 1029-1055. https://doi.org/10.1111/etap.12254.

Nambisan, S., Siegel, D., \& Kenney, M. (2018). On open innovation, platforms, and entrepreneurship. Strategic Entrepreneurship Journal, 12(3), 354-368. https://doi. org/10.1002/sej.1300.

Nambisan, S., Wright, M., \& Feldman, M. (2019). The digital transformation of innovation and entrepreneurship: Progress, challenges and key themes. Research Policy, 48(8), 1-9. https://doi.org/10.1016/j.respol.2019.03.018.

Navis, C., \& Glynn, M. A. (2011). Legitimate distinctiveness and the entrepreneurial identity: Influence on investor judgments of new venture plausibility. Academy of Management Review, 36(3), 479-499.

O'Mahony, S., \& Ferraro, F. (2007). The emergence of governance in an open source community. Academy of Management Journal. https://doi.org/10.5465/AMJ.2007.27169153.

Pietrewicz, L. (2018). Emerging trends in entrepreneurial finance: The rise of ICOs. Studia i Materiaty, 27(1/2), 65-78.

Powell, E. E., \& Baker, T. (2014). It's what you make of it: Founder identity and enacting strategic responses to adversity. Academy of Management Journal, 57(5), 1406-1433. https://doi.org/10.5465/amj.2012.0454.

Robb, A. M., \& Robinson, D. T. (2014). The capital structure decisions of new firms. Review of Financial Studies, 27(1), 153-179. https://doi.org/10.1093/rfs/hhs072.

Sarasvathy, S. D. (2001). Causation and effectuation: Toward a theoretical shift from economic inevitability to entrepreneurial contingency. Academy of Management Review, 26(2), 243-263. https://doi.org/10.5465/AMR.2001.4378020.

Scherr, F. C., Sugrue, T. F., \& Ward, J. B. (1993). Financing the small firm start-up: Determinants of debt use. Journal of Entrepreneurial Finance, 3(1), 17-36.

Schwienbacher, A. (2007). A theoretical analysis of optimal financing strategies for different types of capital-constrained entrepreneurs. Journal of Business Venturing, 22(6), 753781. https://doi.org/10.1016/j.jbusvent.2006.07.003.

Schwienbacher, A. (2013). The entrepreneur's investor choice: The impact on later-stage firm development. Journal of Business Venturing, 28(4), 528-545. https://doi.org/10.1016 /j.jbusvent.2012.09.002.

Schwienbacher, A., \& Larralde, B. (2012). Crowdfunding of small entrepreneurial ventures. In D. J. Cumming (Ed.) The Oxford handbook of entrepreneurial finance (pp. 369-391). Oxford University Press.

Seghers, A., Manigart, S., \& Vanacker, T. (2012). The impact of human and social capital on entrepreneurs' knowledge of finance alternatives. Journal of Small Business Management, 50(1), 63-86. https://doi.org/10.1111/j.1540627X.2011.00344.x.

Shepherd, D. A., Williams, T. A., \& Patzelt, H. (2015). Thinking about entrepreneurial decision making: Review and research agenda. Journal of Management, 41(1), 11-46. https://doi. org/10.1177/0149206314541153.

Sørensen, M. (2007). How smart is smart money? A two-sided matching model of venture capital. Journal of Finance,
62(6), 2725-2762. https://doi.org/10.1111/j.15406261.2007.01291.x.

Tajfel, H., \& Turner, J. C. (1979). An integrative theory of intergroup conflict. In The social psychology of intergroup relations (pp. 33-47). https://doi.org/10.1016/S0065-2601(05 )37005-5.

Vanacker, T. R., \& Manigart, S. (2010). Pecking order and debt capacity considerations for high-growth companies seeking financing. Small Business Economics. https://doi. org/10.1007/s11187-008-9150-x.

Vaznyte, E., \& Andries, P. (2019). Entrepreneurial orientation and start-ups' external financing. Journal of Business Venturing. https://doi.org/10.5465/ambpp.2018.13368abstract.

von Briel, F., Davidsson, P., \& Recker, J. (2018). Digital technologies as external enablers of new venture creation in the it hardware sector. Entrepreneurship: Theory and Practice, 42(1), 47-69. https://doi. org/10.1177/1042258717732779.

von Krogh, G., \& von Hippel, E. (2006). The promise of research on open source software. Management Science. https://doi. org/10.1287/mnsc. 1060.0560 .

Walthoff-Borm, X., Schwienbacher, A., \& Vanacker, T. (2018). Equity crowdfunding: First resort or last resort? Journal of Business Venturing, 33(4), 513-533. https://doi.org/10.1016 /j.jbusvent.2018.04.001.

Wareham, J., Fox, P. B., \& Giner, J. L. C. (2014). Technology ecosystem governance. Organization Science, 25(4), 11951215. https://doi.org/10.1287/orsc.2014.0895.

Weber, R. P. (1990). Basic content analysis (2nd edn.). Newbury Park, Calif.

Winborg, J., \& Landström, H. (2001). Financial bootstrapping in small businesses: Examining small business managers' resource acquisition behaviors. Journal of Business Venturing, 16(3), 235-254. https://doi.org/10.1016/S0883-9026(99)00055-5.

Winton, A., \& Yerramilli, V. (2008). Entrepreneurial finance: Banks versus venture capital. Journal of Financial Economics, 88(1), 51-79. https://doi.org/10.1016/j. jfineco.2007.05.004.

Wright, A., \& De Filippi, P. (2015). Decentralized blockchain technology and the rise of lex cryptographia. SSRN Electronic Journal. https://doi.org/10.2139/ssrn.2580664.

Wright, M., Lumpkin, T., Chris, Z., \& Agarwal, R. (2016). The evolving entrepreneurial finance landscape. Strategic Entrepreneurship Journal, 10(3), 229-234 https://doi. org/10.1002/sej.1232.

Yin, R. K. (2003). Case study research: design and methods (Vol. 3). SAGE publications. https://doi.org/10.1097/FCH.0b013e31822 dda9e.

York, J. G., O’Neil, I., \& Sarasvathy, S. D. (2016). Exploring environmental entrepreneurship: identity coupling, venture goals, and stakeholder incentives. Journal of Management Studies, 53(5), 695-737. https://doi.org/10.1111/joms.12198.

Zuzul, T., \& Tripsas, M. (2019). Start-up inertia versus flexibility: The role of founder identity in a nascent industry. Administrative Science Quarterly. https://doi.org/10.1177 /0001839219843486.

Publisher's note Springer Nature remains neutral with regard to jurisdictional claims in published maps and institutional affiliations. 